\title{
Comparison of dietary phospholipids and neutral lipids on skeletal development and fatty acid composition in Atlantic cod (Gadus morhua)
}

\author{
Elin Kjørsvik ${ }^{a}{ }^{*}$, Cecilia Olsen ${ }^{\mathrm{a}, 1}$, Per-Arvid Wold ${ }^{\mathrm{a}}$, Katja Hoehne-Reitan ${ }^{\mathrm{a}}$, Chantal L. Cahu ${ }^{\mathrm{b}}$, \\ José Rainuzzo ${ }^{c}$, Atle Ivar Olsen ${ }^{a}, d$, Gunvor $\varnothing e^{c}$ and Yngvar Olsen ${ }^{a}$
}

\footnotetext{
a The Norwegian University of Science and Technology, Department of Biology, N-7491 Trondheim, Norway

b IFREMER, UMR 1067 Fish Nutrition, 29280 Plouzané, France

c SINTEF Fisheries and Aquaculture, N-7465 Trondheim, Norway

${ }^{d}$ Nesna University College, N-8700 Nesna, Norway

${ }^{1}$ Present address: Cod Juveniles AS, Mørkved, N-8028 Bodø, Norway
}

*: Corresponding author : Elin Kjørsvik, Tel.: + 47735963 13; fax: + 47735963 11, email address :
Elin.Kjorsvik@bio.ntnu.no

\begin{abstract}
:
Dietary essential fatty acids may affect larval skeletal formation. The aim of this study was to compare effects on growth and osteological development of dietary docosahexaenoic acid (DHA) and eicosapentaenoic acid (EPA) being incorporated in the phospholipid (diets PL1 and PL3) or in the neutral lipid (diet NL1) fraction of the larval diet for Atlantic cod (Gadus morhua). The diets were labelled according to the estimated percentage of total $n-3$ fatty acids contained in the dietary neutral lipid (NL1-1.3\% of dietary dry matter) or in the phospholipid fraction (PL1-1.1\% and PL3-2.3\%). Larvae were weaned to the isoenergetic and isolipidic microdiets from 17 days post hatching (dph). They were co-fed enriched rotifers until $24 \mathrm{dph}$ and received thereafter only the experimental diets until $45 \mathrm{dph}$ (at $\left.12^{\circ} \mathrm{C}\right)$.
\end{abstract}

Dry weight on 45 dph was significantly higher in the PL1- and PL3-larvae (mean $2.74 \pm 0.2 \mathrm{mg} \mathrm{DW}$ ) than in the NL1-larvae (mean $2.17 \pm 0.1 \mathrm{mg} \mathrm{DW}$ ). Larvae fed the PL3-diet had a significantly higher DHA content than larvae from the other treatments. No differences were found in larval content of EPA and arachidonic acid (ARA). Larvae fed both PL-diets showed a significantly faster ossification of the vertebral column compared to larvae fed the NL1-diet, according to both larval size and age. On 45 dph, PL3-larvae also had a significantly higher number of fin rays than the other groups at comparable larval sizes. Deformities (mainly kyphosis and shortened vertebrae) were observed in $11 \%$ (all groups) of the larvae on $45 \mathrm{dph}$, with no significant differences among the groups.

Ossification of the vertebral column in the cod larvae was first observed in the neural arches on the anterior part of the spine (21 dph, > $6.9 \mathrm{~mm}$ standard length, $\mathrm{SL}$ ), followed by the vertebrae ( $25 \mathrm{dph},>$ $7.9 \mathrm{~mm} \mathrm{SL}$ ), haemal arches (31 dph, $\geq 8.4 \mathrm{~mm} \mathrm{SL}$ ) and parapophysis (35 dph, > $8.7 \mathrm{~mm} \mathrm{SL}$ ). Ossification of all vertebral elements was observed in 45-day-old larvae $\geq 11.4 \mathrm{~mm} \mathrm{SL}$. Large variations between larvae in number of ossifying structures between 31 and $35 \mathrm{dph}$ demonstrated that this was the period of most rapid skeletal change (size range $8.2-11.4 \mathrm{~mm} \mathrm{SL}$ ), and that the ossification process was more susceptible to fatty acid lipid source rather than to quantity of dietary fatty acids. We suggest that an optimal dietary content of $n-3$ HUFA in feed for cod larvae is higher than in the PL1-diet.

Keywords: Gadus morhua; Cod; Fish larvae; Osteological development; Skeletal deformities; Dietary requirements; Phospholipids; Fatty acids; EPA; DHA 


\section{Introduction}

Atlantic cod (Gadus morhua L.) has an increasing importance in commercial cold water marine aquaculture, and the production of high quality juveniles is still a bottleneck. One of the problems in hatchery reared cod is the presence of skeletal malformations, especially those affecting the anterior part of the vertebral column. Skeletal malformations in cod juveniles from commercial hatcheries have varied between 25 - 85\% (Lein et al. 2006), and this has negative implications for fish welfare and is causing economic losses to the producers.

Malformations in fish may partly be attributed to suboptimal larval nutrition (Lall and LewisMcCrea 2007). Nutritional factors (Cahu et al. 2003a, b), rearing conditions (Daoulas et al. 1991; Andrades et al. 1996; Boglione et al. 2001; 2003), and genetics (McKay et al. 1986, Sadler et al. 2001; Kolstad et al. 2006) play essential roles in the skeletal development of fish larvae and may be correlated to abnormalities. Deficiencies in dietary components such as essential fatty acids, phospholipids, amino acids, peptides, vitamins and minerals (Kanazawa et al. 1981; Tacon 1992; Gapasin et al. 1998; Cahu et al. 2003a; b) can interfere with the normal development of larvae, affecting fry quality. However, relatively few studies have been carried out on nutritional requirements in first feeding cod (Rosenlund and Halldorsson 2007).

Few studies have been related to the role of essential fatty acids in marine larval bone development (Cahu et al., 2003b; Villeneuve et al., 2005). Bones of marine fish may contain high concentrations of lipids (Phleger, 1991), and with relatively higher proportions of PUFAs than in mammals. The HUFA requirements of marine fish vary both qualitatively and 
quantitatively (Rainuzzo et al. 1997; Sargent et al. 1999; Izquierdo, 2004), and the optimal level of EPA and DHA in marine finfish larvae seem to be about 3\% of dietary dry matter (Cahu and Zambonino Infante, 2001; Sargent et al., 2002). Cod larvae seem to have relatively high requirements for DHA and EPA, especially in the earliest days of feeding (Galloway et al., 1999; O`Brien-MacDonald et al. 2006).

Most studies determining HUFA requirements in fish larvae have been conducted with live prey enriched with fish oils, where EPA and DHA are mainly incorporated in the dominating triacylglycerides (TAG) (Izquierdo et al. 2000). Thus, the effect of lipid classes, such as phospholipids (PL) and neutral lipids (NL) is little studied, although dietary phospholipids are essential for larval development (Coutteau et al. 1997; Cahu et al. 2003b). Cahu et al. (2003a) found that growth and skeletal deformities during early development in sea bass (Dicentrarchus labrax) were more linked to the proportions of dietary PL and NL than to the total dietary lipid content. Furthermore, Gisbert et al. (2005) concluded that dietary PL was more efficient than NL for PUFA supply in European sea bass larvae.

Despite the growing interest in cod, only few studies have described osteological development in cod larvae (Morrison 1993; Grotmol et al. 2005), and there are no controlled, experimental studies of the skeletal development related to larval size or dietary factors in cod.

Understanding of osteological ontogeny is important to eliminate abnormal development under rearing conditions, as this may be induced as early as during the embryonic and larval stages (Daoulas et al. 1991). The notochord, which constitutes the main axial support during embryonic and early larval stages, begins at the neurocranium and ends at the root of the tail fin. Ring-shaped mineralized zones, known as chordacentra; develop segmentally within the notochordal sheath, forming the initial anlagen of the vertebral bodies (Grotmol et al. 2003; 
98

Fleming et al. 2004). Then, sclerotomal osteoblasts condense around the notochord on the surface of the chordacentra, utilising them as foundations for further growth of the vertebrae through direct ossification. The complete vertebral column is formed by the vertebral bodies with their typical hour-glass shape together with other sclerotomal structures, such as neural and haemal arches and the parapophysis (Harder 1975).

The aim of the present study was to compare effects on growth and osteological development of dietary DHA and EPA being incorporated either in the phospholipid (PL) or in the neutral lipid (NL) fraction of the larval feed for Atlantic cod (Gadus morhua), and to study effects of different n-3 HUFA levels in the dietary PL fraction. The experimental design was based on cod larvae fed isolipidic and isoproteic microdiets from 17 dph until 45 days post hatch.

\section{Materials and methods}

\subsection{Larval rearing.}

Atlantic cod eggs were received 2 days before hatching from a commercial hatchery. They were disinfected in a seawater solution of 400 ppm glutaraldehyde for 5 minutes (Salvesen and Vadstein 1995) before transfer to $160 \mathrm{l}$ cone bottomed tanks at densities of $150 \mathrm{egg} \mathrm{l}^{-1}$. After hatching, the temperature was gradually increased from 7.5 to $12^{\circ} \mathrm{C}$ within 6 days and was maintained at $12^{\circ} \mathrm{C} \pm 0.2^{\circ} \mathrm{C}$ throughout the experiment. Water exchange was gradually increased from $0.1 \mathrm{l} \mathrm{min}^{-1}$ to $0.9 \mathrm{l} \mathrm{min}^{-1}$, and the larvae were reared under continuous light conditions (40 W bulbs). 
121 Rotifers were cultivated for five days in 20 ppt sea water at $20^{\circ} \mathrm{C}$, before starting a daily $20 \%$

122 dilution rate of the cultures (Olsen et al., 1993; Olsen, 2004). The rotifers were long term-

123 enriched with Baker's yeast supplemented with $10 \%$ of the marine lipid emulsion "Marol E"

124 (produced by SINTEF Fisheries and Aquaculture, Norway; Wold et al., 2008a).

125

126 Cod larvae were fed rotifers three times every day from $3 \mathrm{dph}$. The feed density was $3000-$

1275000 individuals $\mathrm{L}^{-1}$ until $4 \mathrm{dph}$, and then increased to 5000-7000 individuals $\mathrm{L}^{-1}$ from 5 dph.

128 Algal paste (Nannochloropsis sp.; Reed Mariculture, Campbell, California, USA) was added

129 from 2 dph until the end of the rotifer phase in a concentration of 2 mg Carbon $\mathrm{L}^{-1}$ three

130 times a day. From 17 to 24 dph, there was an overlap between rotifers and formulated diets

131 with a gradual reduction in the amounts of rotifers. From $24 \mathrm{dph}$, cod larvae were fed

132 formulated diets exclusively. Small amounts of the formulated diets were fed manually to the 133 larvae $(0.15 \mathrm{~g} \mathrm{x} 10)$ on day 17 to start weaning. On $18 \mathrm{dph}, 3 \mathrm{~g} \mathrm{day}^{-1}$ of formulated diets were

134 added using continuous automatic belt feeders, gradually increasing the amount of feed added 135 per day to each tank to $10 \mathrm{~g}$ from $31 \mathrm{dph}$. A pellet size of $<200 \mathrm{~lm}$ was used from 17 to 30

136 dph with an increase to 200-400 lm from $30 \mathrm{dph}$. An overlap using a mixture of both pellet

137 sizes was conducted from 30 to $36 \mathrm{dph}$.

138 Each treatment was run with three replicate tanks. Mortality was registered daily from $18 \mathrm{dph}$.

139 The experiments and treatment of all larvae were conducted according to the

140 Norwegian ”Animal Protection Law".

$142 \quad 2.2$ Experimental treatments.

143 Three isoproteinic and isolipidic diets, which varied in lipid class composition were used

144 (Table 1; see also Gisbert et al. 2005). The diets were labelled according to the estimated 145 percentage of n-3 fatty acids contained in the neutral lipid (NL1) or in the phospholipid 
146 fraction (PL1 and PL3) of the diets. In the PL3 and PL1 diets, marine lecithin was

147 incorporated in two different levels into the diets in an inverse relation to soybean lecithin,

148 whereas NL1 contained only soybean lecithin as the PL source and marine TAG (cod liver oil)

149 (Table 1). PL1 and NL1 diets had comparable EPA and DHA levels, either in the

150 phospholipid (PL1) or in the neutral lipid (NL1) fraction. The PL3 diet contained twice the

151 amount of EPA and DHA in the PL fraction compared to PL1 (Table 1). The diets were

152 manufactured by UMR 1067 of Fish Nutrition IFREMER (France). The diets were similar to

153 those used by Gisbert et al. (2005), and further details of diet production, composition and

154 analyses of diet for lipid, protein, and ash content is described in that publication (op. cit.).

155 Feed particle sizes were $<200 \mu \mathrm{m}$ and $200-400 \mu \mathrm{m}$.

156

$157 \quad 2.3$ Sampling.

158 All larval sampling was carried out randomly from the tanks. The sampled larvae were

159 anaesthetized in 3-aminobenzoic acid ethyl ester (MS222, Tamro 257675) and rinsed in

160 freshwater before further treatment.

161

162 For dry weight (DW), 15 larvae were sampled per tank on 1, 10, 17, 24, 35, and 45 dph.

163 Larvae sampled for dry weight were transferred individually to pre-weighed lightweight tin

164 capsules, dried at $60^{\circ} \mathrm{C}$ for $48 \mathrm{~h}$ and weighed on a micro balance (Mettler Toledo microgram

165 balance UMX2,max $2.1 \mathrm{~g}, \mathrm{~d}=0.1$, Switzerland).

166

167 For fatty acid analysis, 15 larvae were sampled from all tanks on $17 \mathrm{dph}$, and 15 larvae per

168 tank were sampled on 24, 35 and 45 dph. The samples were flushed with $\mathrm{N}_{2}$ and kept frozen 169 at $-80{ }^{\circ} \mathrm{C}$. 
171 For osteological development and malformation incidences, 10-15 larvae were collected per

172 treatment $(1,6,10,13,17$, and $21 \mathrm{dph})$ and per tank (25, 31, 35, and $45 \mathrm{dph})$. They were fixed

173 in 10\% formalin in phosphate buffered saline (pH 7.4, Apotekerproduksjon AS, Norway) and

174 stored at $4^{\circ} \mathrm{C}$.

175

176

\subsection{Growth and survival}

177 The larval specific growth rate (SGR) and the daily weight increase (DWI in \% per day) was

178 calculated according to Kjørsvik et al. (2004):

179

$180 \quad \mathrm{SGR}=\ln \left(\mathrm{W}_{\mathrm{t}} / \mathrm{W}_{0}\right) / \mathrm{t}$

181

where $\mathrm{W}_{0}$ is the initial individual dry weight and $\mathrm{W}_{\mathrm{t}}$ is the individual dry weight at time $\mathrm{t}$.

182

183

$\% \mathrm{DWI}=\left(e^{\mathrm{SGR}}-1\right) \times 100$

184

Larval survival was calculated by daily counting of dead larvae from $17 \mathrm{dph}$, and by counting

remaining larvae at the end of the experiment. Numbers were corrected for sampled larvae.

\subsection{Fatty acid analyses of diets and larvae}

Lipid content of eggs and diets was extracted by use of a modified method of Bligh and Dyer (1959) and total lipids were determined gravimetrically according to Rainuzzo et al. (1992). An internal standard 19: 0 methyl ester (Nu-Chek Prep, U.S.A) was added to the samples before extraction. Fatty acid methyl esters (FAMEs) were prepared using the method of Metcalfe et al. (1966) and modified by Rainuzzo et al. (1992). FAMEs were quantified by

194 a capillary gas chromatograph (Perkin Elmer, AutoSystem XL, USA) equipped with a PPC 
195 flame ionization detector and WCOT Fused Silica, coasting CP-Wax 52 CB capillary column

196 (Chromopack, the Netherlands). The gas chromatograph oven was set to increase from an 197 initial $90{ }^{\circ} \mathrm{C}$ to $150{ }^{\circ} \mathrm{C}$ at the rate of $30{ }^{\circ} \mathrm{C} / \mathrm{min}$, and thereafter at $3{ }^{\circ} \mathrm{C} / \mathrm{min}$ to the final

198 temperature of $225{ }^{\circ} \mathrm{C}$. Helium was used as carrier gas. The fatty acids were identified

199 according to a commercial standard (68 D, Nu-Chek Prep, U.S.A ) and quantified according

200 to the response compared to the internal standard. Two replicates of of each diet and three

201 replicates per treatment of the cod larvae were used to determine total lipid and fatty acid 202 composition

\subsection{Histological analyses.}

205 For analyses of bone ossification and osteological abnormalities, 10-20 larvae from each treatment and sampling day were stained in alizarin red (C. I. 58005, Sigma, USA), according to Balon (1985). Fixed larvae were rinsed twice in distilled water for 5 min, dehydrated in ethanol (95\%, 75\%, 40\%, and 15\%, 30 min each) and rinsed in distilled water for $30 \mathrm{~min}$. To remove pigments, larvae were bleached until transparent in a 1:9 ratio of $1 \% \mathrm{KOH}$ and hydrogen peroxide (30\% $\mathrm{H}_{2} \mathrm{O}_{2}, 10$ min to $2 \mathrm{~h}$ ) under strong illumination. Larvae were then cleared using trypsin (T7409, Sigma, USA) dissolved in 0.3\% borate buffer for up to 20h until all muscle tissue was transparent. Following trypsin treatment, larvae were stained for calcified structures by immersion in a $1 \% \mathrm{KOH}$ solution with a few drops of an alizarin red

214 solution to obtain a deep purple colour. Two photos of each larva were taken before the larvae 215 were individually stored in plastic trays in $100 \%$ glycerine with a few crystals of thymol 216 (gradual transfer to 40, 70 and 100\% glycerine).

218 The remaining fixed larvae were stained in Alcian blue (8GS(8GX), USA) and Alizarin red 219 following the staining procedure used by Balon (1985), with the addition of a neutralization 
220

221

222

223

224 Observations were made with a stereo light microscope (Leica MZ75; Germany) equipped 225 accomplished.

step to increase the pH after staining in Alcian blue (after Gavaia et al., 2000). The $45 \mathrm{dph}$ larvae from this group were analysed for fin ray development (18-22 larvae per treatment). All stained larvae were examined for occurrence of osteological abnormalities. with a Sony CCD-IRIS colour video camera (model DXC-107P, Sony, Japan). The standard length (SL, from the tip of the snout to the end of the notochord), and myotome height ( $\mathrm{MH}$, muscle thickness behind the anus) were measured by an ocular micrometer in fixed larvae prior to staining. Development of skeletal elements were identified, and neural and haemal arches, vertebrae and parapophysis during the ossification process were counted under a stereomicroscope and/or by photo analysis (Scion Image Program, Scion Corporation). This software was also used to perform fin ray counts in $45 \mathrm{dph}$ larvae and measurements of spinal curvature and swim bladder area. Types of skeletal malformations and incidences per treatment in each stage were registered.

\subsection{Statistics.}

Results are given as mean values and standard error. Survival and malformation rates were arcsin transformed. Dry weight, fatty acid composition, standard length, number of spinal column elements undergoing ossification, fin ray counts, swim bladder size and incidences of malformations were tested for homogeneity of variances using a Levene test. To compare means, the group data were statistically tested using one-way ANOVA followed by a Student-Newman- 
245 To test a potential difference in the ossification process between the treatments, a forward246 stepwise regression was used to find the best sigmoidal fit to the larval standard length of the

247 three groups. Expected values were calculated using the sigmoidal, and the residuals were 248 calculated as the difference between the expected and observed value. The residuals of 249 ossifying elements were compared between the three feeding groups, using using one-way 250 ANOVA followed by a Student-Newman-Keuls-Test. If significant differences were not 251 found, larval ossification process was grouped according to larval standard length intervals 252 (6.5 - $7.49 \mathrm{~mm}$, etc) and was tested for differences using one-way ANOVA followed by a 253 Student-Newman-Keuls-Test. Differences and effects were considered significant at $\mathrm{P}<0.05$ 254 for all tests. All statistical analysis was performed using the software SPSS 15.0 for Windows. 255

\section{Results}

\subsection{Larval growth and survival}

259 At the end of the experiment (45 dph), the mean dry weight of PL3- $(2.67 \pm 0.7 \mathrm{mg})$ and PL1260 larvae $(2.78 \pm 1.4 \mathrm{mg})$ were significantly higher than for the NL1-larvae $(2.17 \pm 0.1 \mathrm{mg})$, as 261 showed in Figure 1. The mean daily weight increase (DWI) for the experimental period 17 26245 dph was 9.1 - 10.1 \% per day for all treatments, and between 8.3 - 8.9 \% per day from 263 hatching and to $45 \mathrm{dph}$, with no significant difference between the groups (Table 2). Survival 264 during the dry feed period did not differ significantly between treatments on $45 \mathrm{dph}$, being $26512.2 \pm 0.5 \%$ for PL3-larvae, $12.8 \pm 3.5$ for PL1-larvae and $15.7 \pm 4.5$ for NL1-larvae. 


\subsection{Fatty acid composition}

The PL3 diet (Table 3), which contained the highest amount of marine lecithin, had a significantly higher content of DHA than the other diets (15\% of total fatty acids), whereas the EPA-content of diet NL1 was higher than in any of the other diets. The DHA/EPA ratio of PL-diets was 1.8-2.0, with a lower value of 1.1 for the NL1-diet, and the EPA/ARA ratio was higher in NL1 (10.2) compared to the PL-diets (6.8 - 7.3).

The fatty acid composition of the cod larvae on 45 dph reflected the dietary content (Table 3). Larval DHA-content (Figure 2a) at the end of the rotifer stage (17 dph) was about $15 \mathrm{mg} / \mathrm{g}$ dry weight (19\% of total fatty acids). The DHA content increased significantly up to $45 \mathrm{dph}$ in the PL3-group, and the PL3-larvae had a significantly higher DHA-content than the other larvae on both 35 and 45 dph. No differences in DHA-content was found between the PL1and NL1-larvae, and no quantitative differences were found between any larval groups in EPA- or ARA-content at the end of the experiment (Figure 2 b,c).

The DHA/EPA ratios were 3.8 - 3.9 in the PL-larvae, and 2.5 in larvae fed the NL1-diet, and EPA/ARA ratios were 5.9 for the NL1-larvae and 4.3 - 4.6 in PL-larvae (Table 3). Larvae fed NL1- and PL1-diets had higher contents of n-6 HUFAs than the PL3-larvae, and the ratio of n-3/n-6 was significantly higher for PL3-larvae than for NL1- and PL1-larvae (Table 3).

\subsection{Ossification of the spinal column elements}

In larvae sampled for bone development, no differences were found in mean larval standard length on any sampling day between the dietary treaments (Table 4). The first signs of vertebral ossification was observed in 21 day old larvae from all treatments (Table 4), and ossification of all vertebral elements and fin rays were observed on $45 \mathrm{dph}$ in the largest larvae in all treatments (Fig. 3). 
293 An overview of the age related ossification and mean size of larvae is given in Table 4. The

294 first elements of the vertebral column to undergo ossification were the neural arches.

295 Ossification of these structures was observed from $21 \mathrm{dph}$. Ossification of the vertebrae began 296 in larvae $\geq 7.8 \mathrm{~mm}$ SL from $25 \mathrm{dph}$, and ossification of haemal arches was first observed in 29731 dph larvae ( $\geq 8.1 \mathrm{~mm} \mathrm{SL}$ ). The ossification process increased rapidly between 25-45 dph, 298 and large variations in numbers of ossifying neural and haemal arches and vertebrae were 299 especially found in all larval groups on 31 and $35 \mathrm{dph}$. On $31 \mathrm{dph}$, the mean SL of stained 300 larvae from all treatments were similar (8.4-8.5 mm), and PL3-larvae had a significantly 301 higher mean number of ossifying neural arches and vertebrae than the NL1-larvae, with PL1302 larval values in between these groups (Table 4). A marked age related delay in ossification 303 was thus observed in the NL1-larvae. After $31 \mathrm{dph}$, no difference was found in age related ossification of the vertebral column elements (Table 4).

A size related comparison of the development of ossifying structures demonstrated a size dependent and rapid increase in ossification of larvae $>8 \mathrm{~mm}$ SL for all treatments (Fig. 4).

308 Ossification of neural arches was observed in larvae from $6.9-8.6 \mathrm{~mm} \mathrm{SL}$, and all fifty pairs could be observed in larvae from $11.1 \mathrm{~mm}$ SL (Fig. 4a). Normal larvae had straight vertebrae during the ossification process, and ossification of all fifty vertebrae was observed in the largest larvae ( $\geq 12.0 \mathrm{~mm} \mathrm{SL}$ ) from all treatments on 45 dph (Table 4; Figs 3 and 4b).

312 Ossifying haemal arches were observed from $8.1 \mathrm{~mm}$ SL, and complete ossification of all 31 313 haemal arches was observed in larvae $\geq 10.6$ mm SL (Fig. 4c). The best fit curve found was the Gompertz growth curves (Fig. 4), which also demonstrated a tendency of higher variation and slower size related ossification of all vertebral elements in 
317 the NL1-larvae compared to PL-larvae. While $90 \%$ of PL-larvae reached forty ossified

318 neural arches at $9 \mathrm{~mm}$ SL, the same was observed in NL-larvae only from $12 \mathrm{~mm}$ length (Fig.

319 4a). Likewise, $90 \%$ of the PL-larvae underwent ossification to forty vertebrae at a range of

$320 \quad 8.2-11.4 \mathrm{~mm}$ SL, whereas larvae fed NL1 diet reached this stage at the size interval of 8.4 -

$32111.8 \mathrm{~mm}$ SL (Fig. 4b). Larvae in the PL-groups reached ossification of 11 haemal arches

322 mainly in larvae from the PL groups at 8.2 - 9.7 mm SL, whereas the same stage was seen in

323 a much wider size range in larvae fed NL1 (8.2 - $11.4 \mathrm{~mm}$ SL, Fig. 4c). No significant

324 differences in the ossification process were found between PL- and NL-larvae using the

325 residuals of ossifying elements in the Gompertz models ( $\mathrm{p}>0.05$ ), mainly due to the large

326 variation in larvae from the NL1-group.

328 Comparing development of ossifying vertebral elements in larval size intervals (Fig. 5)

329 demonstrated further the tendency to slower size related ossification in the NL1-larvae, 330 especially between 8.5 - 11.5 mm SL. However, large individual variations were observed, 331 and only ossification of the haemal arches showed a significantly slower development in 332 NL1-larvae than in the PL-larvae ( $<<0.05$; Fig. 5c).

334 Ossification of parapophysis was first observed in 35 dph larvae ( $>8.7 \mathrm{~mm}$ SL) reaching full 335 ossification in the largest 45 dph larvae (Table 4). No significant differences were found 336 between the diets.

338 Development of fin rays on 45 dph (Fig. 3) was significantly more advanced in larvae fed 339 PL3 compared to PL1 and NL1 larval groups (Table 5). The fin ray development was 340 correlated to the larval size in all treatments, and small larvae from all groups had lower 341 number of fin rays than bigger larvae (Pearson correlation, $\mathrm{p}<0.01$ ). However, the PL3 larvae 
342 had a higher number of fin rays than the other groups at comparable larval sizes $(p<0.05)$. In

343 the NL1 group, the caudal and $1^{\text {st }}$ dorsal fins had the most variable ray numbers. Some of the

344 larvae from this group had not yet developed rays in the $1^{\text {st }}$ dorsal fin, and at the end of the

345 experiment the NL1 larvae also had lower mean caudal fin ray numbers compared to the

346 larvae fed PL.

\subsection{Incidences of malformations and types.}

No significant difference was found between the groups with respect to the incidences of malformations at any sampling day. No skeletal abnormalities were observed on 1, 10 and 13 dph, and very low malformation rates were seen until 35 dph (Fig 6a). Skeletal malformations were found in $11 \%$ (all groups pooled) of the larvae on $45 \mathrm{dph}$, where kyphosis and shortened vertebrae in the anterior part of the spine accounted for $81 \%$ of the total observed malformations (Figs. 6b, 7a, 7b). Very few larvae with scoliosis and lordosis (Figs. 6b, 7b), and only one larvae with cephalic malformation (jaw deformity) were observed. In addition to spinal malformations, deformities of fin rays and pterygiophores were found in $6 \%$ of the larvae on $45 \mathrm{dph}$.

Vertebral curvature (angle) of the larvae was positively correlated to the number of shortened vertebral segment bodies $(\mathrm{p}<0.01)$, with no significant differences between the diets. No correlation was found between vertebral curvature (deformed larvae) and swim bladder size ( $>0.05$ ). The relation between SL and MH was positively linear for both categories of larvae (normal larvae $\mathrm{R}^{2}=0.7759$ and $\mathrm{p}<0.0001$; abnormal larvae $\mathrm{R}^{2}=0.6480$ and $\mathrm{p}<0.0003$ ). The MH was not significantly different between normal and abnormal larvae ( $p>0.05)$. 


\section{Discussion}

The most important aim of this experiment was to compare possible effects of essential dietary fatty acids being incorporated in different lipid classes. We found that the n-3 HUFAs were clearly more beneficial to larval growth and development when incorporated in the polar

372 phospholipid fraction (PL) than in the neutral lipid (NL) fraction, as demonstrated by higher average dry weight of PL3- and PL1-larvae at the end of the experiment. Larvae fed PL diets also showed a significantly faster ossification of the vertebral column compared to larvae fed the NL diet, when measured both by larval size and by larval age. There was no significant difference in spinal ossification between larvae from the PL1 and PL3 groups. In spite of the difference in growth and skeletal development between NL1- and PL1-larvae, there were no differences in the larval content of DHA, EPA, or ARA between these two larval groups. The larval fatty acid composition clearly reflected the dietary composition, and the only major difference in larval fatty acid composition was the much higher DHA content of PL3-larvae at

381 the end of the experiment. All diets contained the recommended value of $10 \%$ phospholipids 382 and n-3 HUFA contents were above that generally required in larval diets (Sargent et al. 1999). Phospholipids constituted about $60-75 \%$ of the total lipid content in our diets, which is in the same range as found in copepods (van der Meeren et al., 2008). The copepods that are the most important natural larval diet seem to have a DHA-content ranging from about $4 \mathrm{mg} / \mathrm{g}$ DW (van der Meeren et al., 2008) and up to 15-20 mg/g DW (Evjemo et al., 2003), and our experimental diets were within the same range. The DHA/EPA-ratios of these copepods varied between $1.2-2.8$ (op. cit.), which shows that our diets were in the higher end of this scale. We may therefore conclude that fatty acid metabolism and incorporation into cod larval tissues may not only be partly determined by the levels of fatty acids available from the 
391

392

393

394

diet (as reviewed by Sargent et al. 1999), but that it is also strongly affected by the dietary lipid source of the n-3 fatty acids.

All microdiets used in the present study supported positive larval growth and development in Atlantic cod larvae, and larval growth in our experiment was higher than for other early weaning trials with cod (Baskerville-Bridges and Kling, 2000; Wold et al. 2008a). The larval growth rates we obtained in the present study with very early larval weaning, was aso comparable to previous studies of cod larvae fed enriched cultivated prey (Galloway et al., 1999; Brown et al., 2003; Park et al., 2006; van der Meeren et al., 2007; Garcia et al., 2008). However, the larval growth presented here was lower than what we recently obtained for cod using enriched rotifers and Artemia nauplii (Wold et al., 2008a).

In addition to an improved growth, maturation of the digestive system also occurred more rapidly in the cod larvae fed the PL3 and PL1-diets than in larvae fed the NL1 diet (Wold et al., 2007), and the marine phospholipids used in this study had a beneficial effect on the larval liver histology (Wold et al., 2009).

The nutritional benefits of n-3 HUFAs being incorporated in the dietary phospholipid fraction was expressed as a faster developmental rate of ossification of the vertebral column and fin rays in PL-larvae than in NL1-larvae, both according to larval size and age, although all groups demonstrated a size-dependent skeletal ossification. By the end of the experiment (45dph, $540 \mathrm{~d}^{\circ}$ ), ossification of all spinal elements was observed in the largest larvae in all groups ( $\geq 12.0 \mathrm{~mm} \mathrm{SL}$ ). Studies of larval malformations only from the end of the experiment (45 dph) would therefore not have revealed any differences in dietary skeletal effects (except in number of fin rays). 
417 Cod larvae had a straight notochord at hatching (4.4 mm SL), and no developed structures of 418 the axial skeleton were observed. This observation is consistent with previous findings for cod 419 (Grotmol et al. 2005) and for other species like barramundi (Lates calcarifer) (Fraser et al. 420 2004), common Pandora (Pagellus erythrinus) (Sfakianakis et al. 2004) and Senegal sole 421 (Solea senegalesis) (Gavaia et al. 2002), where the notochord was the only axial suspension 422 structure present at hatching. This feature seems to be characteristic for many larval teleostei.

In our study, the first structures to ossify were the neural arches, followed by vertebrae, haemal arches and parapophysis. The onset of skeletal ossification was observed around 21 25 dph (252 -300 d $\left.\mathrm{d}^{\circ}\right) \mathrm{dph}$ (size range of $6.9-8.6 \mathrm{~mm} \mathrm{SL}$ ). Grotmol et al. (2005) also found ossification of the first pair of neural arches in 21 day old cod larvae from commercial hatcheries (fed live prey, 6-11 ${ }^{\circ} \mathrm{C}$ ). The main skeletal development of cod larvae in the present experiment seemed to follow a similar pattern and timing of events as observed in the study by Grotmol et al. (2005). However, a direct comparison of our results is not possible, as data of larval size were not given by Grotmol et al. (2005). To our knowledge, the present study is the first to describe skeletal development in cod larvae related to the larval size as well as to the age and nutritional quality.

The major spinal ossification process occurred in the size range of $8.2-11.4 \mathrm{~mm}$, which mainly corresponded to 31 and 35 days-old larvae. The large variations between larvae in number of ossifying structures between 31 and $35 \mathrm{dph}$, demonstrated that this was the period of most rapid skeletal change. In this developmental window, the ossification process was more susceptible to fatty acid lipid source rather than to the quantity of dietary fatty acids. 
441 Similar significant differences between treatments in fin ray numbers were found at the end of 442 the experiment, and larvae fed PL3 had significantly higher dorsal, anal, and caudal fin rays 443 number than larvae fed PL1 and NL1 at comparable larval size and age. Fin rays are sensitive 444 to environmental influences, especially to thermal variation (Boglione et al. 2001). However, 445 this could not be the cause of fin ray variation found in this study, since larvae from the three 446 treatments had the same rearing conditions, differing from each other only in the microdiets 447 they were fed. The results thus demonstrated that larvae fed the highest level of EPA + DHA 448 in the PL fraction (PL3), developed faster than the other larval groups. A rapid increase in 449 size and development of fin rays should be energetically beneficial for the swimming and 450 predatory ability of cod larvae, due to the length dependence between inertial and viscous 451 forces acting on swimming fish larvae, and to the functionality and effectivity of the larval 452 swimming apparatus (Osse and van den Boogart 1995; 2004; Galloway et al. 1999).

454 Larval deformities were relatively low in the present experiment (11\%) compared to observations from commercial hatcheries, where abnormalities of the vertebral bodies on the 456 anterior part of the spine have been observed in up to 85\% of the juveniles (Lein et al., 2006).

457 The high rate of normally developing larvae is probably due to our high quality enriched 458 rotifers, and is further indicating that the different experimental diets did not induce high 459 frequencies of malformations. Cod larvae in our experiment were mainly affected by 460 kyphosis and shortened vertebrae of the anterior part of the spine, while cases of jaw 461 malformation, lordosis and scoliosis were rarely found.

The main types of malformations which were found in the present study were thus in line with similar observations from marine larval hatcheries (Andrades et al. 1996; Daoulas et al. 1991; Totland et al. 2004, Grotmol et al. 2005; Lein et al. 2006). Multiple variations in rearing 
conditions, diets and genetic material will affect spinal deformity rates in cod (Kolstad et al., 2006), which makes it difficult to elucidate the causative factors in these earlier studies with cod. Imsland et al. (2006), found that cod juveniles where larvae had been fed cultivated enriched rotifers had a much higher incidence of caudal spinal deformities than juveniles startfed with natural zooplankton, with 14 and 4\% deformities in the two different groups. Similar caudal deformities was not observed in our experiment. However, Imsland et al. (2006) used Nannochloropsis for enrichment of rotifers, and these microalgae contain very little n-3 HUFAs compared to other microalgae used in fish larviculture, such as e.g. Isochrysis galbana (Reitan et al., 1997). It is therefore possible that the caudal deformities observed in intensively reared cod by Imsland et al. (2006) could have been induced by a lack of essential n-3 HUFAs in the larval feed.

Possible factors related to kyphosis malformations have been reported in a few studies, but with contradictory conclusions. In reared juveniles of sea bass, kyphosis has been related to the non-inflation of the swim bladder, but has also been observed in sea bass larvae with a normal functional swim bladder (Koumoundouros et al. 2002). In striped trumpeter (Latris lineate), hyperinflation of the swim bladder has been related to kyphosis (Trotter et al. 2001). Grotmol et al. (2005) observed that this deformity developed as early as $7 \mathrm{dph}$ in cod, during the transition to live feed and two weeks before ossification of the vertebral column components was observed. The critical time window with regard to development of this malformation seemed to be from 18 to $36 \mathrm{dph}$, when the initial formation of the vertebrae took place, and Grotmol et al. (2005) concluded that the probable causes for kyphosis in cod larvae were an overfilled swim bladder which pressed the notochord upwards. However, such a relation between anomalies of swim bladder and kyphotic larvae was not found in our study. In contrast to the results of Grotmol et al. (2005), we observed kyphosis deformities mainly at 
491

492 nor the size of the swim bladder was related to malformations of the vertebral bodies. Thus, 493 an increased swim bladder size can not be the only cause for spinal deformities in cod larvae, 494 although it may be a problem in some larval rearing systems.

495

later stages (35-45 days after hatching). In our study, neither the difference between the diets

Long-chain n-3 PUFAs seem effective in promoting bone formation in mammals as well as in fish (Lall and Lewis-McCrea, 2007), but these mechanisms are poorly studied in fish. Feeding n-3 PUFAs to growing male rats elevated EPA and DHA, but reduced ARA in various bone tissue compartments, reduced ex vivo bone prostaglandin E2 production, and increased rates of bone formation (Watkins et al. 2000). Increasing dietary DHA also lowered the ratio of 18:2n-6 (linoleic acid)/n-3 in bone compartments, which favoured bone formation as well as bone conservation in rats (Watkins et al. 2003; 2006). Larvae fed NL1 and PL1 diets contained relatively more n-6 HUFAs than the PL3-larvae, thus increasing the ratio of n-6/n3. The better bone formation in all PL-larvae compared to NL1-larvae might thus be explained by better availability of the n-3 HUFAs in the PL-diets, as the percentage of n-3 HUFAs was quite similar in both the NL1- and PL1-diets.

The high dietary content of phosphatidylinositol (PI) from 2 to $2.5 \%$ (see Table 1 ) could explain the relatively low malformation rates and that no significant differences were found between the groups in the present study of cod larvae. The content of PI in the three diets were higher than recommended for sea bass (1.6\%, Cahu et al. 2003a) and carp (Cyprinus carpio) (1.3\%, Geurden et al. 1998), where this content resulted in only $2 \%$ of deformed larvae. In sea bass larvae, where the same diets as used in the present study, were used from the beginning of exogenous feeding, the PL1 and PL3 diets resulted in good larval growth and survival, with low vertebral deformities, whereas similar levels of DHA and EPA 
516 incorporated in the NL were suppressing the growth or were even lethal (Gisbert et al., 2005;

517 Villeneuve et al., 2005). Higher levels of HUFAs also showed that retinoid pathways were

518 negatively influenced by dietary lipids, leading to skeletal malformation in the sea bass larvae

519 (Villeneuve et al., 2005).

520

521 From our cod larval feeding experiment, using the same formulated diets as in Gisbert et al.

522 (2005) as an “Artemia replacement”, we conclude that the essential n-3 HUFAs were more

523 beneficial for the cod larval growth and skeletal development when they were supplied in the

524 dietary polar phospholipids rather than in the dietary neutral lipids. Larvae fed the PL-diets,

525 with EPA and DHA in the PL fraction, showed a faster ossification than larvae fed n-3 HUFA

526 in the neutral lipid fraction (NL1), and spinal ossification rate and fin ray formation related to

527 larval size were sensitive parameters for dietary osteological effects in cod larvae. Based upon

528 the results from larval fatty acid content and fin ray formation, we suggest that n-3 HUFA

529 requirements in cod larvae is higher than in the PL1 diet. However, further studies should be

530 conducted to find the optimal level of essential HUFAs in the dietary PL fraction for

531 developing cod larvae, and to reveal the mechanisms affected by dietary lipids in larval bone

532 development.

533

\section{Acknowledgements}

535 The authors wish to thank the Norwegian Research Council for funding through the research

536 projects “CODTECH - A process oriented approach to intensive production of marine

537 juveniles with main emphasis on cod" (NRC 153422/120) and "Effects of phospholipid

538 supplement in microdiets during co-feeding of marine fish larvae” (NRC 142025/120), and

539 the Norwegian University for Science and Technology for funding of P.-A. Wold (PhD

540 scholarship). We also thank T. Bardal for her excellent technical assistance, H. Quang 
541 Nguyen for very good discussions and advice regarding the statistics, and G. Koumoundouros 542 for his valuable comments.

543 


\section{References}

546 Andrades, J. A., Becerra, J., Fernández-Lebrez, P. 1996., Skeletal deformities in larval,

547 juvenile and adult stages of cultured gilthead sea bream (Sparus aurata L.). Aquaculture $548 \quad 141,1-11$.

549 Balon, E. K., 1985. Microscopic techniques for studies of early ontogeny in fishes: problems 550 and methods of composite descriptions. In: E.K. Balon (Ed.), Early life histories of fishes: 551 New developmental, ecological and evolutionary perspectives. Dr. W. Junk Publishers, $552 \quad$ Lancaster, pp. 33-35.

553 Baskerville-Bridges, B., Kling, L.J., 2000. Early weaning of Atlantic cod (Gadus morhua) $554 \quad$ larvae onto a microparticulate diet. Aquaculture 189, 109-117.

555 Bligh, E.G., Dyer, W.J., 1959. A rapid method of total lipid extraction and purification. $556 \quad$ Canadian Journal of Biochemistry and Physiology 37, 911-917.

557 Boglione, C., Gagliardi, F., Scardi, M., Cataudella, S., 2001. Skeletal descriptors and quality 558 assessment in larvae and post-larvae of wild-caught and hatchery-reared gilthead sea 559 bream (Sparus aurata L. 1758). Aquaculture 192, 1-22.

560 Boglione, C., Costa, C., di Pato, P., Ferzini, G., Scardi, M., Cataudella, S., 2003. Skeletal 561 quality assessment of reared and wild sharpsnout sea bream and pandora juveniles. $562 \quad$ Aquaculture 227, 373-394.

563 Brown, J.A., Minkoff, G., Puvanendran, V. 2003. Larviculture of Atlantic cod (Gadus 564 morhua): progress, protocols and problems. Aquaculture 227, 357-372

565 Cahu, C., Zambonino Infante, J., 2001. Substitution of live food by formulated diets in marine 566 fish larvae. Aquaculture 200,162-180. 
567 Cahu, C., Zambonino Infante, J., Barbosa, V., 2003a. Effect of dietary phospholipid level and

568 phospholipid:neutral lipid value on the development of sea bass (Dicentrarchus labrax)

569 larvae fed a compound diet. Journal of Nutrition 90, 21-28.

570 Cahu, C., Zambonino Infante, J., Takeushi, T., 2003b. Nutritional components affecting

$571 \quad$ skeletal development in fish larvae. Aquaculture 227, 245-258.

572 Cotteau, P., Geurden, I., Camara, M. R., Bergot, P., Sorgeloos, P., 1997. Review on the

573 dietary effects of phospholipids in fish and crustacean larviculture. Aquaculture 155, 149-

$574 \quad 164$.

575 Daoulas, C. H., Economou, N. A., Bantavas, I., 1991. Osteological abnormalities in

576 laboratory reared sea bass (Dicentrachus labrax) fingerlings. Aquaculture 97, 169-180.

577 Evjemo, J.O., Reitan, K.I., Olsen, Y., 2003. Copepods as live food organisms in the larval

578 rearing of halibut larvae (Hippoglossus hippoglossus L.) with special emphasis on the $579 \quad$ nutritional value. Aquaculture 227, 191-210.

580 Fleming, A., Keynes, R., Tannahill, D., 2004. A central role for the notochord in vertebral $581 \quad$ patterning. Development 131, 873-880.

582 Fraser, M. R., Anderson, T. A., de Nys, R., 2004. Ontogenic development of the spine and 583 spinal deformities in larval barramundi (Lates calcarifer) culture. Aquaculture 242, 697584711.

585 Galloway, T. F., Kjørsvik, E., Kryvi, H., 1999. Muscle growth and development in Atlantic 586 cod larvae (Gadus morhua L.) related to different somatic growth rates. Journal of $587 \quad$ Experimental Biology 202, 2111-2120.

588 Gapasin, R. S. J., Bombeo, R., Lavens, P., Sorgeloos, P., Nelis, H., 1998. Enrichment of live 589 food with essential fatty acids and vitamin C: effects on milkfish (Chanos chanos) larval $590 \quad$ performance. Aquaculture 162, 269-286. 
591 Garcia, A.S., Parrish, C.C., Brown, J.A. 2008. A comparison among differently enriched

592 rotifers (Brachionus plicatilis) and their effect on Atlantic cod (Gadus morhua) larvae

593 early growth, suvival and lipid composition. Aquaculture Nutrition 14, 14-30.

594 Gavaia, P. J., Sarasquete, M. C., Cancela, M. L., 2000. Detection of mineralized structures in 595 very early stages of development of marine teleostei using a modified Alcian blue-

596 Alizarin red double staining technique for bone and cartilage. Biotechnology and $597 \quad$ Histochemistry $75,79-84$.

598 Gavaia, P. J., Dinis, M. T., Cancela, M. L. 2002. Osteological development and abnormalities 599 of the vertebral column and caudal skeleton in larval and juvenile stages of hatchery$600 \quad$ reared Senegal sole (Solea senegalensis). Aquaculture 211, 305-323.

601 Geurden, I., Marion, D., Charlon, N., Coutteau, P., Bergot, P. 1998. Comparison of different 602 soybean phospholipidic fractions as dietary supplements for common carp, Cyprinus 603 carpio, larvae. Aquaculture 161, 225-235.

604 Gisbert, E., Villeneuve, L., Zambonino-Infante, J.L., Quazuguel, P., Cahu, C.L. 2005. Dietary 605 phospholipids are more efficient than neutral lipids for long-chain polyunsaturated fatty 606 acid supply in European sea bass Dicentrarchus labrax larval development. Lipids 40, 1$607 \quad 11$.

608 Grotmol, S., Kryvi, H., Nordvik, K., Totland, G. K. 2003. Notochord segmentation may lay 609 down the pathway for the development of the vertebral bodies in the Atlantic salmon. $610 \quad$ Anatomy and Embryology 207, 263-272.

611 Grotmol, S., Kryvi, H., Totland, G. H. 2005. Deformation of the notochord by pressure from 612 the swim bladder may cause malformation of the vertebral column in cultured Atlantic 613 cod Gadus morhua larvae: a case study. Diseases of Aquatic Organisms 65, 121-128. 614 Harder, W. 1975. Anatomy of Fishes: Part I. E Schweizerbartsche Verlagsbuchhandlung 615 (Nägele u Obermiller), E. Schweizerbart'sche, Stuttgart. 612 pp. 
616 Imsland, A.K., Foss, A., Koedjik, R., Folkvord, A., Stefansson, S.O., Jonassen, T.M., 2006.

617 Short- and long-term differences in growth, feed conversion efficiency and deformities in 618 juvenile Atlantic cod (Gadus morhua) startfed on rotifers or zooplankton. Aquaculture $619 \quad$ Research 37, 1015-1027.

620 Izquierdo, M. S., Socorro, J., Arantzamendi, L., Hernandez-Cruz, C. M., 2000. Recent 621 advances in lipid nutrition in fish larvae. Fish Physiology and Biochemistry 22, 97-107.

622 Izquierdo, M. S., 2004. Nutritional requirements for finfish larvae. The Second Hatchery, 623 Feeds and Technology Workshop, 30 September-1 October 2004, Sidney, Australia, $624 \quad$ pp.8-16.

625 Kanazawa, A., Teshima, S., Inamori, S., Iwashita, T., Nagao, A., 1981. Effects of 626 phospholipids on growth, survival rate and incidence of malformation in the larval ayu. 627 Mem. Fac. Fish. Kagishima Univ. 30, 301-309.

628 Kolstad, K., Thorland, I., Refstie, T., and Gjerde, B. 2006. Genetic variation and genotype by 629 location interaction in body weight, spinal deformity and sexual maturity in Atlantic cod 630 (Gadus morhua) reared at different locations off Norway. Aquaculture 259, 66-73.

631 Koumoundouros, G., Maingot, E., Divanach, P., Kentouri, M., 2002. Kyphosis in reared sea 632 bass (Dicentrarchus labrax L.): ontogeny and effects on mortality. Aquaculture 209, 4963358.

634 Kjørsvik, E., Pittman, K., Pavlov, D., 2004. From fertilization to the end of metamorphosis 635 functional development. In: Moksness, E., Kjørsvik, E., Olsen, Y. (Eds.), Culture of Cold$636 \quad$ Water Marine Fish. Blackwell Science, Blackwell Publishing Ltd, Oxford, pp 204-278. 637 Lall, S.P., Lewis-McCrea, L.M., 2007. Role of nutrients in skeletal metabolism and pathology 638 in fish - An overview. Aquaculture 267, 3-19. 
639 Lein, I., Bæverfjord, G., Hjelde, K., Helland, S., 2006. Assessment of deformities in cod

640 (Kartlegging av deformiteter hos torsk). Akvaforsk Rapport No. 1/06, 13 pp (In

$641 \quad$ Norwegian).

642 Metcalfe, L.D., Schimtz, A.A., Pelka, J.R., 1966. Rapid preparation of fatty acids esters from 643 lipids for gas chromatography. Anal. Chem. 38, 514- 515.

644 McKay, L. R., Gjerde, B., 1986. Genetic variation for a spinal deformity in Atlantic salmon, 645 Salmo salar. Aquaculture 52, 263-272.

646 Morrison, C. M., 1993. Histology of the Atlantic cod, Gadus morhua: An Atlas. Part Four:

647 Eleutheroembryo and Larva. Canadian Special Publication in Fisheries and Aquatic $648 \quad$ Sciences 119, 496 pp.

649 O`Brien-MacDonald, K., Brown, J., Parrish, C.C., 2006. Growth, behaviour, and digestive 650 enzyme activity in larval Atlantic cod (Gadus morhua) in relation to rotifer lipid. ICES $651 \quad$ Journal of Marine Science 63, 275-284.

652 Olsen, Y., Reitan, K.I., Vadstein, O., 1993. Dependence of temperature on loss rates of 653 rotifers lipids and N3 fatty acids in starved Brachionus plicatilis cultures. Hydrobiologia $654 \quad 255 / 256,13-20$.

655 Olsen, Y., van der Meeren, T., Reitan, K.I., 2004. First feeding technology. In: Moksness, E., 656 Kjørsvik, E., Olsen, Y. (Eds.), Culture of cold-water marine fish. Blackwell Publishing $657 \quad$ Ltd., pp. 279-336.

658 Osse, J.W.M., van den Boogaart, J.G.M., 1995. Fish larvae, development, allometric growth, 659 and the aquatic environment. ICES Marine Science Symposium 201, 21-34.

660 Osse, J. W. M., and van den Boogaart, G. M. 2004. Allometric growth in fish larvae: timing 661 and function. American Fisheries Society Symposium 40: 167-194. 
662 Phleger, C.F., 1991. Biochemical aspects of buoyancy in fishes. In: Hochachka, P.W.,

663 Mommsen, T.P. (Eds.), Biochemistry and Molecular Biology of Fishes. Phylogenetic and 664 Biochemical Perspectives, vol. I. Elsevier, Amsterdam, pp. 209-347.

665 Park, H.G., Puvanendran, V., Kellett, A., Parrish, C.C., Brown, J.A., 2006. Effect of enriched 666 rotifers on growth, survival, and composition of larval Atlantic cod (Gadus morhua).

667 ICES Journal of Marine Sciences 63, 285-295.

668 Rainuzzo J. R., Reitan K. I. and Jorgensen L. (1992). Comparative study on the fatty acid and 669 lipid composition of four marine fish larvae. Comp. Biochem. Physiol. 103B, 21-26.

670 Rainuzzo, J., Reitan, K. I., Olsen, Y., 1997. The significance of lipids at early stages of 671 marine fish: a review. Aquaculture 155, 103-115.

672 Reitan, K.I., Rainuzzo, J.R., Øie, G., Olsen, Y. 1997. A review of the nutritional effects of 673 algae in marine fish larvae. Aquaculture 155, 207-221.

674 Rosenlund, G., Halldórsson, Ó., 2007. Cod juvenile production: Research and commercial 675 developments. Aquaculture 268, 188-194.

676 Sadler, J., Pankhurst, P. M., King, H. R., 2001. High prevalence of skeletal deformity and 677 reduced gill surface area in triploid Atlantic salmon (Salmo salar L.). Aquaculture 198, $678 \quad 369-386$.

679 Salvesen, I., Vadstein, O. 1995. Surface disinfection of eggs from marine fish: evaluation of 680 four chemicals. Aquaculture International 3, 155-171.

681 Sargent, J.R., Mc Evoy, L., Estévez, A., Bell, G., Bell, M., Henderson, J., Tocher, D., 1999. 682 Lipid nutrition in marine fish during early development: Current status and future 683 directions. Aquaculture 79, 217-230.

684 Sargent, J. R., Tocher, D. R., Bell, J. G., 2002. The lipids. In: Fish Nutrition. Halver, J. E and 685 Hardy, R. W. (eds). Academic Press. pp. 182-257. 
Sfakianakis, D. G., Koumoundouros, G., Anezki, L., Divanach, P., Kentouri, M., 2004. Osteological development of the vertebral column and of the fins in Pagellus erythrinus (L. 1758). Temperature effect on the developmental plasticity and morpho-anatomical abnormalities. Aquaculture 232, 407-424.

Tacon, A. G. J., 1992. Nutritional fish pathology. Morphological signs of nutrient deficiency and toxicity in farmed fish. FAO Fisheries Technical Paper no 330, Rome. 75 pp.

Totland, G. K., Kryvi, H., Grotmol, S., 2004. Cod juveniles with "bent neck” is one of the maijor problems in intensive cultivation today (Torskeyngel med "nakkeknekk” utgjør et av hovedproblemene i intensivt oppdrett i dag). Havbruksrapport, 57-63. (In Norwegian)

Trotter, A. J., Pankhurst, P. M., Hart, P. R., 2001. Swim bladder malformation in hatcheryreared striped trumpeter Latris lineata (Latridae). Aquaculture 198, 41-54.

van der Meeren, T., Mangor-Jensen, A., Pickova, J. 2007. The effect of green water and light intensity on survival, growth and lipid composition in Atlantic cod (Gadus morhua) during intensive larval rearing. Aquaculture 265, 206-217.

van der Meeren, T., Olsen, R.E., Hamre, K., Fyhn, H.J. 2008. Biochemical composition of copepods for evaluation of feed quality in production of juvenile marine fish. Aquaculture 274, 375-397.

Villeneuve, V.L., Gisbert, E., Zambonino-Infante, J.L., Quazuguel, P., Cahu, C.L. 2005. Effect of nature of dietary lipids on European sea bass morphogenesis: implication of retinoid receptors. Britsih Journal of Nutrition 94, 877-884.

Watkins BA, Li Y, Allen KGD, Hoffmann WE, Seifert MF., 2000. Dietary ratio of (n-6)/(n-3) polyunsaturated fatty acids alters the fatty acid composition of bone compartments and biomarkers of bone formation in rats. Journal of Nutrition 130, 2274- 84. 
709 Watkins BA, Li Y, Lippman HE, Feng S., 2003. Modulatory effect of omega-3

710 polyunsaturated fatty acids on osteoblast function and bone metabolism. Prostaglandins

$711 \quad$ Leukot Essent Fatty Acids, 68: 387-98.

712 Watkins, B.A., Li, Y., Seifert, M.F., 2006. Dietary ratio of n-6/n-3 PUFAs and

713 docosahexaenoic acid: actions on bone mineral and serum biomarkers in ovariectomized

714 rats. Journal of Nutritional Biochemistry 17, 282- 289.

715 Wold, P.-A, Hoehne-Reitan, K., Cahu, C.L., Zambonino Infante, J. L., Rainuzzo, J., Kjørsvik,

716 E., 2007. Phospholipids vs. neutral lipids: Effects on digestive enzymes in Atlantic cod

717 (Gadus morhua) larvae. Aquaculture 272, 502-513.

718 Wold, P.-A, Hoehne-Reitan, K., Rainuzzo, J. Kjørsvik, E., 2008a. Allometric growth and 719 functional development of the gut in developing cod (Gadus morhua) larvae. Journal of $720 \quad$ Fish Biology, 72, 1637-1658.

721 Wold, P.-A., Hoehne-Reitan, K., Cahu, C-L., Zambonino Infante, J., Rainuzzo, J., Kjørsvik, E. 722 (2009). Comparison of dietary phospholipids and neutral lipids: effects on gut, liver and 723 pancreas histology in Atlantic cod (Gadus morha L.) larvae. Aquaculture Nutrition, 15, $724 \quad 73-84$ 
Table 1. Ingredients and proximate composition of the experimental microdiets. The diets were similar to those used by Gisbert et al. (2005), and further details of diet production, composition and analyses of diet for lipid, protein, and ash content is described in that publication (op. cit.).

\begin{tabular}{|c|c|c|c|}
\hline Diet & PL3 & PL1 & NL1 \\
\hline \multicolumn{4}{|c|}{ Ingredients $^{\mathrm{a}}$ (g/100 g dry matter) } \\
\hline Defatted fish meal & 51 & 51 & 51 \\
\hline Hydrolyzed fish meal (CPSP) & 14 & 14 & 14 \\
\hline Cod liver oil & 0 & 0 & 7 \\
\hline Marine lecithin ${ }^{\mathrm{b}}$ & 14 & 7 & 0 \\
\hline Soybean lecithin ${ }^{\mathrm{C}}$ & 7 & 14 & 14 \\
\hline Vitamin mixture $^{\mathrm{d}}$ & 8 & 8 & 8 \\
\hline Mineral mixture ${ }^{\mathrm{e}}$ & 4 & 4 & 4 \\
\hline Betain & 2 & 2 & 2 \\
\hline \multicolumn{4}{|l|}{ Proximate composition \% } \\
\hline Proteins (N x 6.25) & 61.5 & 58.3 & 57.7 \\
\hline Lipids & 16.1 & 16.4 & 17.9 \\
\hline Phospholipids & 12.5 & 12.4 & 10.7 \\
\hline $\mathrm{EPA}+\mathrm{DHA}$ in PL & 2.3 & 1.1 & 0.3 \\
\hline Neutral lipids & 3.7 & 4.4 & 6.8 \\
\hline $\mathrm{EPA} \pm \mathrm{DHA}$ in NL & 0.3 & 0.3 & 1.3 \\
\hline Ash & 17.4 & 17.5 & 17.4 \\
\hline Moisture & 7.5 & 7.1 & 7.2 \\
\hline Energy $(\mathrm{MJ} / \mathrm{kg})^{\mathrm{f}}$ & 16.34 & 15.92 & 16.39 \\
\hline
\end{tabular}

${ }^{a}$ All dietary ingredients were commercially available. Fish meal (La Lorientaise, Lorient, France), hydrolyzed fish meal (CPSP, Soluble Fish Protein Concentrate; Sopropêche, Boulogne sur Mer, France), cod liver oil (La Lorientaise), marine lecithin (LC60, Phosphomins ${ }^{\text {TM}}$; Phosphotech, Saint Herblain, France).

${ }^{\mathrm{b}}$ Contains 60\% phospholipids (with 45\% PC, 20\% Phosphatidil Ethanolamine PE, 16\% PI), 5\% TAG, $15 \%$ cholesterol, and $1 \mathrm{mg} / \mathrm{g}$ natural tocopherols as antioxidant.

${ }^{\mathrm{c}}$ Contains 95\% phospholipids (with 26\% PC, 20\% PE and 14\% PI).

${ }^{\mathrm{d}}$ Per kg of vitamin mix: retinyl acetate $1 \mathrm{~g}$; cholecalciferol $2.5 \mathrm{mg}$; all-rac- $\alpha$-tocopherol acetate $10 \mathrm{~g}$; menadione $1 \mathrm{~g}$; thiamine $1 \mathrm{~g}$; riboflavine $0.4 \mathrm{~g}$; D-calcium pantothenate $2 \mathrm{~g}$; pyridoxine $\mathrm{HCl} 0.3 \mathrm{~g}$; cyanocobalamine $1 \mathrm{~g}$; niacine $1 \mathrm{~g}$; choline chloride $200 \mathrm{~g}$; ascorbate polyphosphate $20 \mathrm{~g}$; folic acid 0.1 g; biotin $1 \mathrm{~g}$; meso-inositol $30 \mathrm{~g}$; cellulose $732.1 \mathrm{~g}$.

${ }^{\mathrm{e}} \mathrm{Per} \mathrm{kg}$ of mineral mixture: $\mathrm{KCl} 90 \mathrm{~g}, \mathrm{Kl}_{4} \mathrm{O} 40 \mathrm{mg}, \mathrm{CaHPO}_{4} \cdot 2 \mathrm{H}_{2} \mathrm{O} 500 \mathrm{~g}, \mathrm{NaCl} 40 \mathrm{~g}, \mathrm{CuSO}_{4} .5 \mathrm{H}_{2} \mathrm{O} 3 \mathrm{~g}$, $\mathrm{ZnSO}_{4} .7 \mathrm{H}_{2} \mathrm{O} 4 \mathrm{~g}, \mathrm{CoSO}_{4} .7 \mathrm{H}_{2} \mathrm{O} 20 \mathrm{mg}, \mathrm{FeSO}_{4} .7 \mathrm{H}_{2} \mathrm{O} 20$ g, $\mathrm{MnSO}_{4} \cdot \mathrm{H}_{2} \mathrm{O} 3 \mathrm{~g}, \mathrm{CaCO}_{3} 215 \mathrm{~g}$, $\mathrm{MgSO}_{4} .7 \mathrm{H}_{2} \mathrm{O} 124 \mathrm{~g}, \mathrm{NaF} 1 \mathrm{~g}$.

${ }^{\mathrm{f}}$ Calculated as: fat x $37.7 \mathrm{MJ} / \mathrm{kg}$; protein x $16.7 \mathrm{MJ} / \mathrm{kg}$. 
749 Table 2. Daily weight increase (DWI) $(\%$, means \pm s.e., $n=3)$ for cod larvae during the

750 microdiet feeding experiment (17 - $45 \mathrm{dph})$ and for the whole larval period ( $0-45 \mathrm{dph})$.

751

\begin{tabular}{|l|c|c|c|}
\hline & \multicolumn{3}{|c|}{ Cod larval DWI (\%) } \\
\hline Period (dph) & NL1 & PL1 & PL3 \\
\hline $17-45$ & $9.1 \pm 0.3$ & $10,1 \pm 0.6$ & $9,7 \pm 0.6$ \\
\hline $0-45$ & $8.3 \pm 0.3$ & $8.9 \pm 0.2$ & $8.6 \pm 0.4$ \\
\hline
\end{tabular}

752

753

754 


\begin{tabular}{|c|c|c|c|c|c|c|}
\hline & & Diets & & & larvae (45 c & \\
\hline & NL1 & PL1 & PL3 & NL1 & PL1 & PL3 \\
\hline Total lipid (mg/g DW) & $232.3 \pm 2.9^{\mathrm{a}}$ & $184.2 \pm 12.1^{\mathrm{a}}$ & $183.6 \pm 3.5^{b}$ & $151.2 \pm 8.8$ & $153.8 \pm 1.7$ & $148,1 \pm 9.9$ \\
\hline Sum FA (mg/g DW) & $94.3 \pm 0.4^{\mathrm{a}}$ & $67.2 \pm 0.6^{\mathrm{a}}$ & $57.8 \pm 0.7^{\mathrm{b}}$ & $61.6 \pm 5.0$ & $64.2 \pm 1.2$ & $61,6 \pm 1.0$ \\
\hline Total n-3 - (mg/g DW) & $15.4+0.1^{\mathrm{a}}$ & $11.3+0.1^{\mathrm{b}}$ & $15.1 \pm 0.5^{\mathrm{a}}$ & $19.8 \pm 0.9^{\mathrm{a}}$ & $21.0 \pm 0.2^{\mathrm{a}}$ & $26.0 \pm 0.3^{\mathrm{b}}$ \\
\hline - (\% of total FA) & $16.3 \pm 0.2^{\mathrm{a}}$ & $16.7+0.0^{\mathrm{a}}$ & $26.2 \pm 0.5^{b}$ & $32.4 \pm 1.6^{\mathrm{a}}$ & $32.6+0.8^{\mathrm{a}}$ & $42.2 \pm 0.5^{\mathrm{b}}$ \\
\hline Total n-6 - (mg/g DW) & $31.7 \pm 0.3^{\mathrm{a}}$ & $27.8 \pm 0.0^{\mathrm{b}}$ & $16.3 \pm 0.1^{\mathrm{c}}$ & $14.0 \pm 2.3^{\mathrm{ab}}$ & $17.1 \pm 1.0^{\mathrm{a}}$ & $9.3 \pm 0.4^{\mathrm{b}}$ \\
\hline$-(\%$ of total FA $)$ & $33.6 \pm 0.2^{\mathrm{a}}$ & $41.3 \pm 0.3^{b}$ & $28.2+0.2^{\mathrm{C}}$ & $22.5 \pm 2.0^{\mathrm{a}}$ & $26.6 \pm 1.0^{\mathrm{a}}$ & $15.1 \pm 0.6^{\mathrm{b}}$ \\
\hline n-3/n-6 ratio & $0.5 \pm 0.0^{\mathrm{a}}$ & $0.4 \pm 0.0^{\mathrm{b}}$ & $0.9 \pm 0.0^{c}$ & $1.5 \pm 0.2^{\mathrm{a}}$ & $1.2 \pm 0.1^{\mathrm{a}}$ & $2.8 \pm 0.1^{\mathrm{b}}$ \\
\hline - (mg/g DW) & $24.4 \pm 0.0^{\mathrm{a}}$ & $17.2 \pm 0.4^{\mathrm{b}}$ & $16.6 \pm 0.1^{\mathrm{b}}$ & $17.2 \pm 1.0$ & $17.4 \pm 0.3$ & $17.0 \pm 0.5$ \\
\hline - (\% of total FA) & $25.9 \pm 0.1^{\mathrm{a}}$ & $25.5 \pm 0.4^{\mathrm{a}}$ & $28.7 \pm 0.2^{\mathrm{b}}$ & $28.0 \pm 0.6$ & $27.1 \pm 0.3$ & $27.5 \pm 0.4$ \\
\hline Monounsaturated FA - (mg/g DW) & $22.8 \pm 0.2^{\mathrm{a}}$ & $11.1 \pm 0.1^{\mathrm{b}}$ & $9.8 \pm 0.0^{c}$ & $10.6 \pm 0.9$ & $8.8 \pm 0.1$ & $9.4 \pm 0.5$ \\
\hline - (\% of total FA) & $24.2 \pm 0.1^{\mathrm{a}}$ & $16.4 \pm 0.1^{\mathrm{b}}$ & $16.4 \pm 0.2^{\mathrm{b}}$ & $17.2 \pm 0.3^{\mathrm{a}}$ & $13.7 \pm 0.2^{\mathrm{b}}$ & $15.2 \pm 0.7^{\mathrm{b}}$ \\
\hline DHA - (mg/g DW) & $5.8 \pm 0.2^{\mathrm{a}}$ & $5.0 \pm 0.1^{\mathrm{a}}$ & $8.7 \pm 0.5^{\mathrm{b}}$ & $13.3 \pm 0.5^{\mathrm{a}}$ & $15.5 \pm 0.3^{\mathrm{a}}$ & $20.0 \pm 0.2^{b}$ \\
\hline - (\% of total FA) & $6.1 \pm 0.2^{\mathrm{a}}$ & $7.4 \pm 0.1^{\mathrm{a}}$ & $15.1+0.6^{\mathrm{b}}$ & $21.9+1.8^{\mathrm{a}}$ & $24.2+0.9^{\mathrm{a}}$ & $32.4+0.6^{\mathrm{b}}$ \\
\hline $\mathrm{EPA}-(\mathrm{mg} / \mathrm{g} \mathrm{DW})$ & $5.1 \pm 0.0^{\mathrm{a}}$ & $2.7 \pm 0.0^{\mathrm{b}}$ & $4.4 \pm 0.1^{\mathrm{c}}$ & $5.3 \pm 0.4$ & $4.1 \pm 0.0$ & $5.2 \pm 0.1$ \\
\hline - (\% of total FA) & $5.5 \pm 0.0^{\mathrm{a}}$ & $4.1 \pm 0.0^{b}$ & $7.5 \pm 0.1^{\mathrm{c}}$ & $8.6 \pm 0.1^{\mathrm{a}}$ & $6.3+0.1^{b}$ & $8.4+0.0^{\mathrm{a}}$ \\
\hline ARA - (mg/g DW) & $0.5+0.0$ & $0.4+0.0$ & $0.6 \overline{+}+0.0$ & $0.9+0.0$ & $0.9+0.0$ & $1.2+0.1$ \\
\hline - (\% of total FA) & $0.5 \pm 0.0^{\mathrm{a}}$ & $0.6 \pm 0.0^{b}$ & $1.1 \pm 0.0^{\mathrm{c}}$ & $1.5 \pm 0.1$ & $1.5 \pm 0.1$ & $1.9 \pm 0.1$ \\
\hline DHA/EPA ratio & $1.1 \pm 0.0$ & $1.8 \pm 0.0$ & $2.0 \pm 0.0$ & $2.5 \pm 0.2$ & $3.8 \pm 0.1$ & $3.9 \pm 0.1$ \\
\hline EPA/ARA ratio & 10.2 & 6.8 & 7.3 & $5.9+0.2$ & $4.6+0.1$ & $4.3+0.1$ \\
\hline
\end{tabular}

Table 3. Lipid and fatty acid content of the experimental microdiets and 45 day old cod larvae at the end of the experiment.

dph, days posthatch; DHA, docosahexaenoic acid; EPA, eicosapentaenoic acid; ARA, arachidonic acid.

758 Values are the mean \pm s.e. of two (diets) or three (larvae) replicates, values with different superscript for diets means dietary values are significantly different $(\mathrm{P}<0.05)$, larval 
762 Table 4. Number of neural and haemal arches, vertebrae and parapophysis (mean \pm s.e.)

763 undergoing ossification in cod larvae fed three microdiets (PL3, PL1, NL1). The larvae were

764 stained in Alizarin Red. Different letters indicate significant differences between the diets at

765 that day $(\mathrm{p}<0.05)$.

766

767

\begin{tabular}{|c|c|c|c|c|c|c|c|}
\hline & & & No. & Neural & & Haemal & Parapophysis \\
\hline Dph & Diet & $\mathrm{SL}(\mathrm{mm})$ & larvae & arches & Vertebrae & arches & \\
\hline \multirow[t]{3}{*}{21} & PL3 & $7.1 \pm 0.2$ & 7 & $0.0 \pm 0.0^{b}$ & 0 & 0 & 0 \\
\hline & PL1 & $6.9 \pm 0.04$ & 6 & $0.2 \pm 0.2^{\mathrm{a}, \mathrm{b}}$ & 0 & 0 & 0 \\
\hline & NL1 & $7.6 \pm 0.08$ & 7 & $0.7 \pm 0.3^{\mathrm{a}}$ & 0 & 0 & 0 \\
\hline \multirow[t]{3}{*}{25} & PL3 & $7.9 \pm 0.05$ & 16 & $3.8 \pm 1.0$ & $2.5 \pm 1.1$ & 0 & 0 \\
\hline & PL1 & $8.2 \pm 0.03$ & 16 & $2.8 \pm 0.7$ & $1.6 \pm 0.7$ & 0 & 0 \\
\hline & NL1 & $7.9 \pm 0.1$ & 15 & $2.5 \pm 1.0$ & $1.1 \pm 0.8$ & 0 & 0 \\
\hline \multirow[t]{3}{*}{31} & PL3 & $8.5 \pm 0.06$ & 12 & $14.8 \pm 3.9^{\mathrm{a}}$ & $12.8 \pm 3.3^{\mathrm{a}}$ & $4.7 \pm 3.5$ & 0 \\
\hline & PL1 & $8.4 \pm 0.06$ & 11 & $10.1 \pm 3.7^{\mathrm{a}, \mathrm{b}}$ & $8.9 \pm 3.0^{\mathrm{a}, \mathrm{b}}$ & $2.2 \pm 1.7$ & 0 \\
\hline & NL1 & $8.4 \pm 0.08$ & 13 & $6.2 \pm 2.6^{\mathrm{b}}$ & $4.3 \pm 1.6^{\mathrm{b}}$ & $1.7 \pm 1.7$ & 0 \\
\hline \multirow[t]{3}{*}{35} & PL3 & $8.7 \pm 0.05$ & 17 & $17.8 \pm 3.4$ & $15.0 \pm 3.6$ & $7.8 \pm 2.0$ & $1.9 \pm 0.3$ \\
\hline & PL1 & $8.9 \pm 0.02$ & 22 & $22.5 \pm 2.9$ & $19.6 \pm 3.6$ & $8.2 \pm 2.0$ & $1.1 \pm 0.2$ \\
\hline & NL1 & $9.5 \pm 0.08$ & 15 & $21.7 \pm 4.2$ & $19.4 \pm 4.3$ & $8.7 \pm 2.5$ & $1.3 \pm 0.3$ \\
\hline \multirow[t]{3}{*}{45} & PL3 & $13.3 \pm 0.09$ & 18 & $48.2 \pm 1.0$ & $43.3 \pm 2.0$ & $30.1 \pm 0.8$ & $7.8 \pm 0.7$ \\
\hline & PL1 & $12.5 \pm 0.07$ & 17 & $48.1 \pm 1.3$ & $44.8 \pm 2.2$ & $31.4 \pm 1.1$ & $8.4 \pm 0.5$ \\
\hline & NL1 & $13.3 \pm 0.01$ & 18 & $46.2 \pm 1.5$ & $43.2 \pm 1.5$ & $27.3 \pm 1.6$ & $8.5 \pm 0.6$ \\
\hline
\end{tabular}


770 Table 5. Cod larval mean number of fin rays on $45 \mathrm{dph}$ (mean values \pm s.e., $\mathrm{n}=18-22$ larvae

771 per treatment), after feeding experimental microdiets from 17 dph. Different letters indicate

772 significant differences between the treatments. Correlation between ray numbers and larval

773 size, r2: Pearson correlation, $\mathrm{p}<0.01$.

774

\begin{tabular}{rcccc}
\hline Character & PL3 & PL1 & NL1 & Correlation \\
\hline 1st dorsal fin & $10.3 \pm 0.3^{\mathrm{a}}$ & $8.6 \pm 0.5^{\mathrm{a}, \mathrm{b}}$ & $7.0 \pm 0.8^{\mathrm{b}}$ & $\mathrm{r}^{2}=0.503$ \\
2nd dorsal fin & $16.6 \pm 0.5^{\mathrm{a}}$ & $13.8 \pm 0.7^{\mathrm{b}}$ & $12.2 \pm 0.7^{\mathrm{b}}$ & $\mathrm{r}^{2}=0.436$ \\
\hline 3rd dorsal fin & $16.2 \pm 0.3^{\mathrm{a}}$ & $14.0 \pm 0.5^{\mathrm{b}}$ & $12.6 \pm 0.8^{\mathrm{b}}$ & $\mathrm{r}^{2}=0.446$ \\
1st anal fin & $18.2 \pm 0.7^{\mathrm{a}}$ & $14.6 \pm 0.7^{\mathrm{b}}$ & $15.7 \pm 0.9^{\mathrm{a}, \mathrm{b}}$ & $\mathrm{r}^{2}=0.541$ \\
2nd anal fin & $16.1 \pm 0.4^{\mathrm{a}}$ & $14.0 \pm 0.4^{\mathrm{b}}$ & $12.9 \pm 0.6^{\mathrm{b}}$ & $\mathrm{r}^{2}=0.356$ \\
Caudal fin & $40.9 \pm 0.7^{\mathrm{a}}$ & $36.5 \pm 1.2^{\mathrm{b}}$ & $34.1 \pm 0.9^{\mathrm{b}}$ & $\mathrm{r}^{2}=0.530$ \\
\hline
\end{tabular}


778

779

780

781

782

783

784

785

786

787

788

789

790

791

792

793

794

795

796

797

798

799

800

\section{Legends to the figures}

Figure 1. Cod larval dry weight during the experiment (mean \pm standard error of the means (s.e.), each point represents 45-67 larvae). Points with different superscript denote significant differences between dietary treatments ( $<$ 0.05). "Co-feeding” represents the weaning period where larvae were fed enriched rotifers and increasing ratios of the experimental diets. The larvae were fed only experimental diets from $24 \mathrm{dph}$.

Figure 2: Cod larval content (mean values + s.e., $\mathrm{n}=3$ ) of docosahexaenoic acid (DHA), eicosapentaenoic acid (EPA), and arachidonic acid (ARA) at the start (17 dph) and during the microdiet feeding experiment. Points with different superscript mean that values between larval contents are significantly different on the specific sampling day $(\mathrm{p}<0.05)$.

Figure 3: Skeletal development in cod larvae at the end of the experiment (45 dph, diet PL3).

a) Larva stained with Alcian Blue and Alizarin Red, demonstrating formation of all fin rays. b) Larva with ossificiation of all elements of the vertebral column, stained with Alizarin Red. The calibration bar equals $1 \mathrm{~mm}$.

Figure 4: Number of neural arches (a), vertebrae (b), and haemal arches (c) undergoing ossification in cod larvae fed the experimental microdiets, in relation to diets and larval size. Each point represents one larva (21, 25, 31, 35 and $45 \mathrm{dph})$, and the best fit curve found was the Gompertz growth model. PL3: Slashed lines, PL1: solid lines, NL1: dotted lines. 
802 Figure 5: Mean number of neural arches (a), vertebrae (b), and haemal arches (c) undergoing 803 ossification, in relation to diets and larval size inetrvals. Delayed ossification of haemal arches 804 was found in NL1-larvae of 10.5-11.49 mm SL. Similar tendencies could e found for all 805 ossifying elements of the vertebral column between SL of 8.5-11.5 mm, but individual 806 variation within treatments was high.

807

808 Figure 6. Skeletal deformities in cod larvae from the experiment. a) Percentage of cod larvae 809 with deformities of the vertebral column from the different dietary treatments $(\mathrm{n}=15 \mathrm{x} 3$ for 810 each column). (b) Percentage of each vertebral deformity type found from each treatment on 81135 and $45 \mathrm{dph}$. No differences were found between the treatments, giving a total of 11\% 812 spinal deformities in the larvae on $45 \mathrm{dph}$.

813

814 Figure 7: Skeletal deformities were found in $11 \%$ of the cod larvae at the end of the 815 experiment (45 dph), with shortened vertebrae and kyphosis accounting for 81\% of the spinal 816 malformations. a) Kyphosis in larva fed NL1-diet. The first eight vertebral bodies and their 817 respective neural arches were deformed. The centre of the deformation is located on the 4th 818 vertebral body, resulting in an A-shape. b) A 45 dph larva (PL1) with fused, shortened and 819 dislocated vertebral bodies in the anterior part of the spine and deformed neural arches of the 820 involved vertebral bodies. The larvae were stained with Alizarin Red, and the calibration bars 821 equals $1 \mathrm{~mm}$.

822 


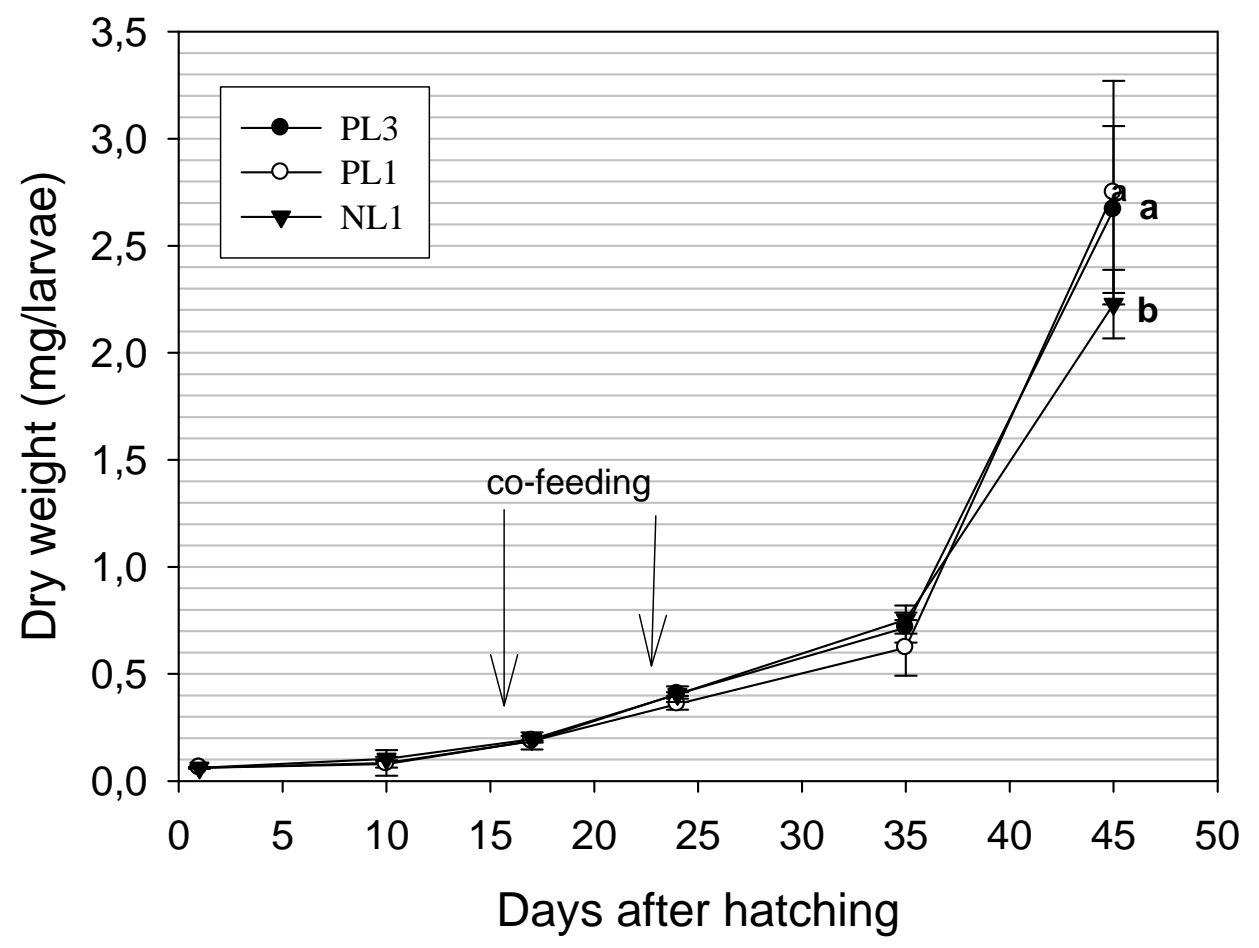

Figure 1. Cod larval dry weight during the experiment (mean \pm standard error of the means (s.e.), each point represents 45-67 larvae). Points with different superscript denote significant differences between dietary treatments $(\mathrm{p}<0.05)$. "Co-feeding” represents the weaning period where larvae were fed enriched rotifers and increasing ratios of the experimental diets. The larvae were fed only experimental diets from $24 \mathrm{dph}$. 
a)

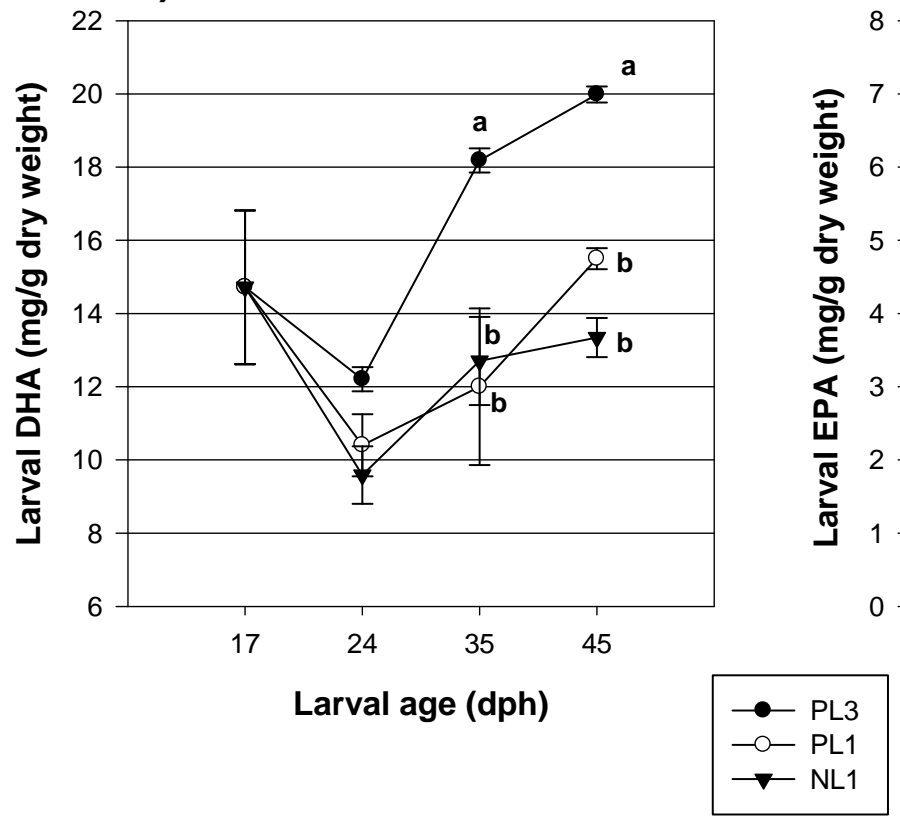

c)

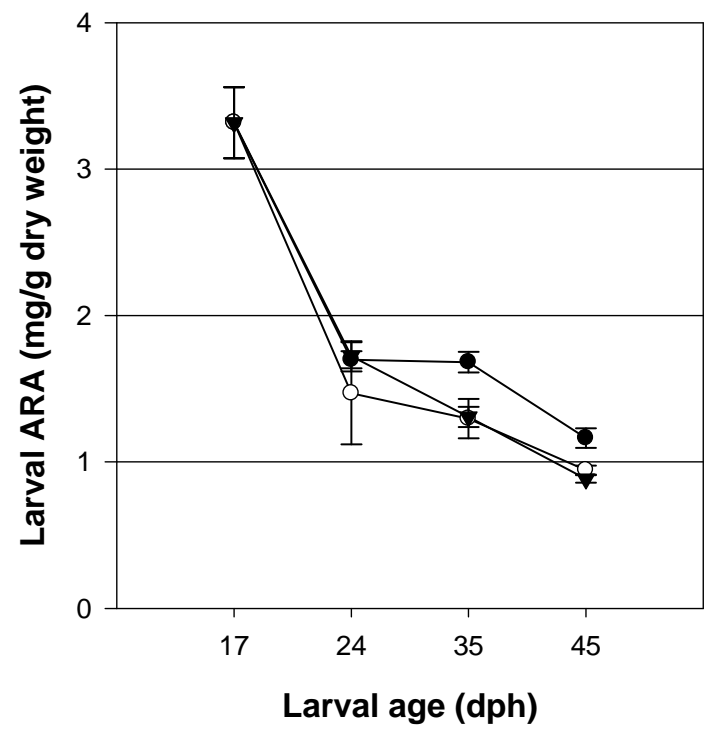

b)

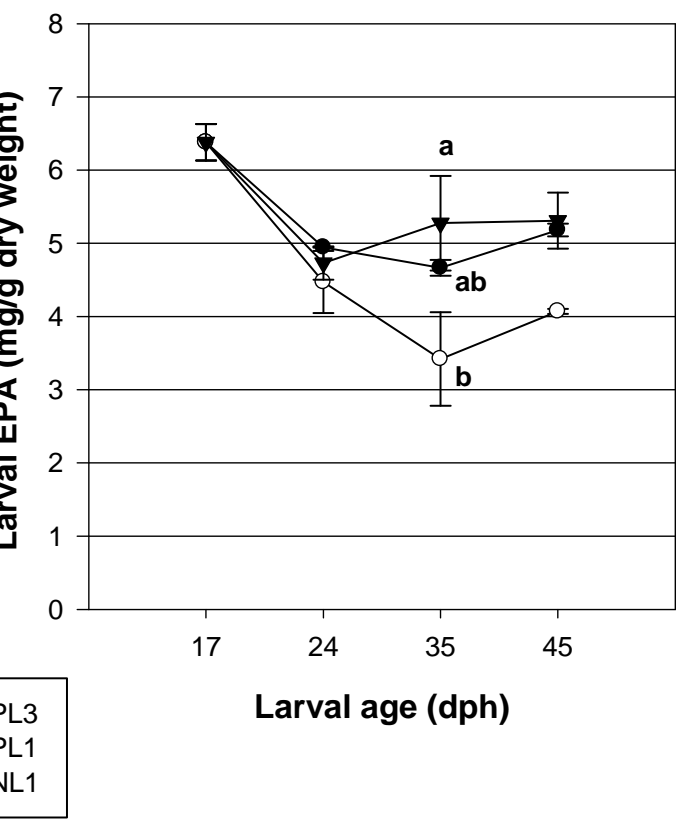




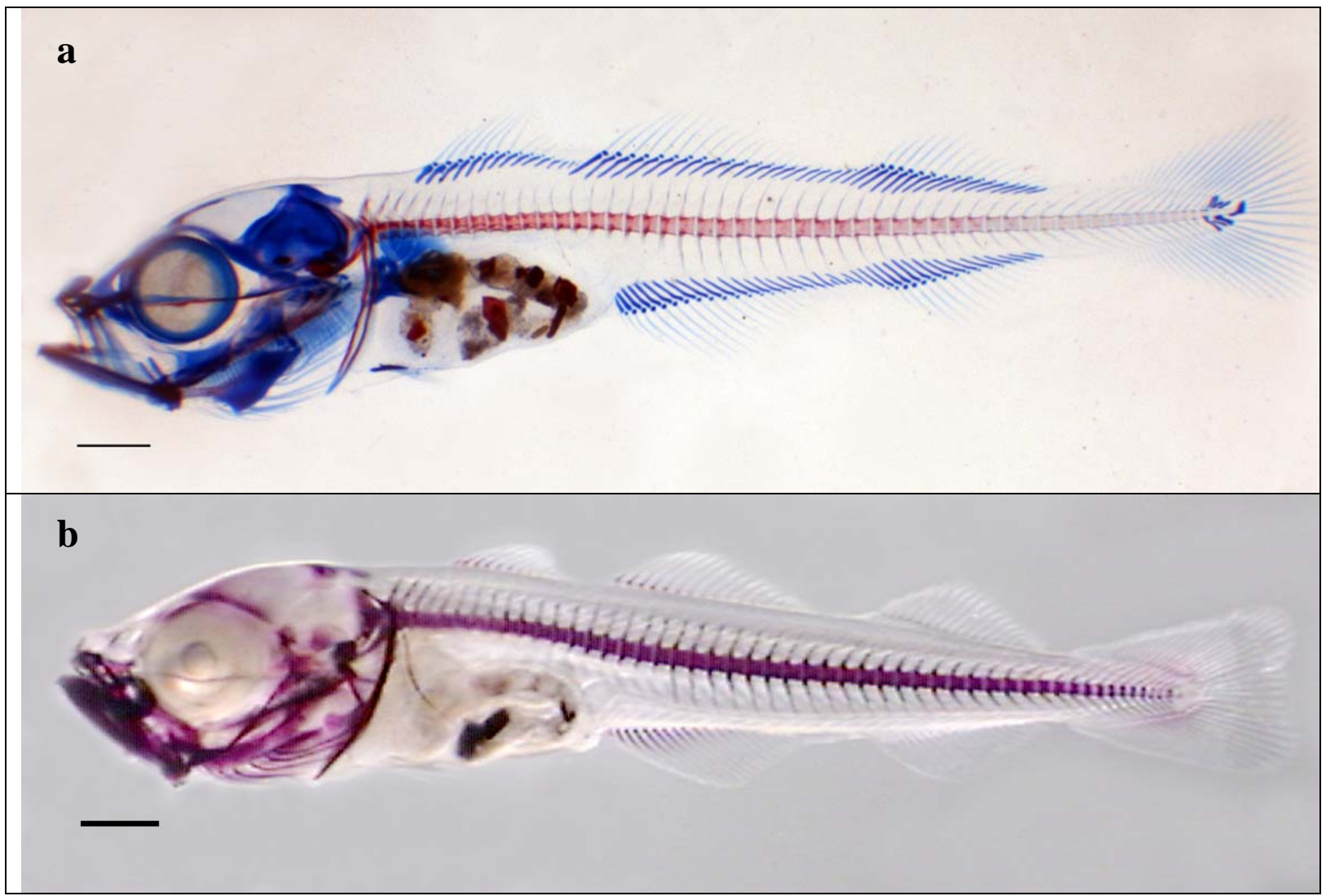

Figure 3: Skeletal development in cod larvae at the end of the experiment (45 dph, diet PL3). a) Larva stained with Alcian Blue and Alizarin Red, demonstrating formation of all fin rays. b) Larva with ossificiation of all elements of the vertebral column, stained with Alizarin Red. The calibration bar equals $1 \mathrm{~mm}$. 


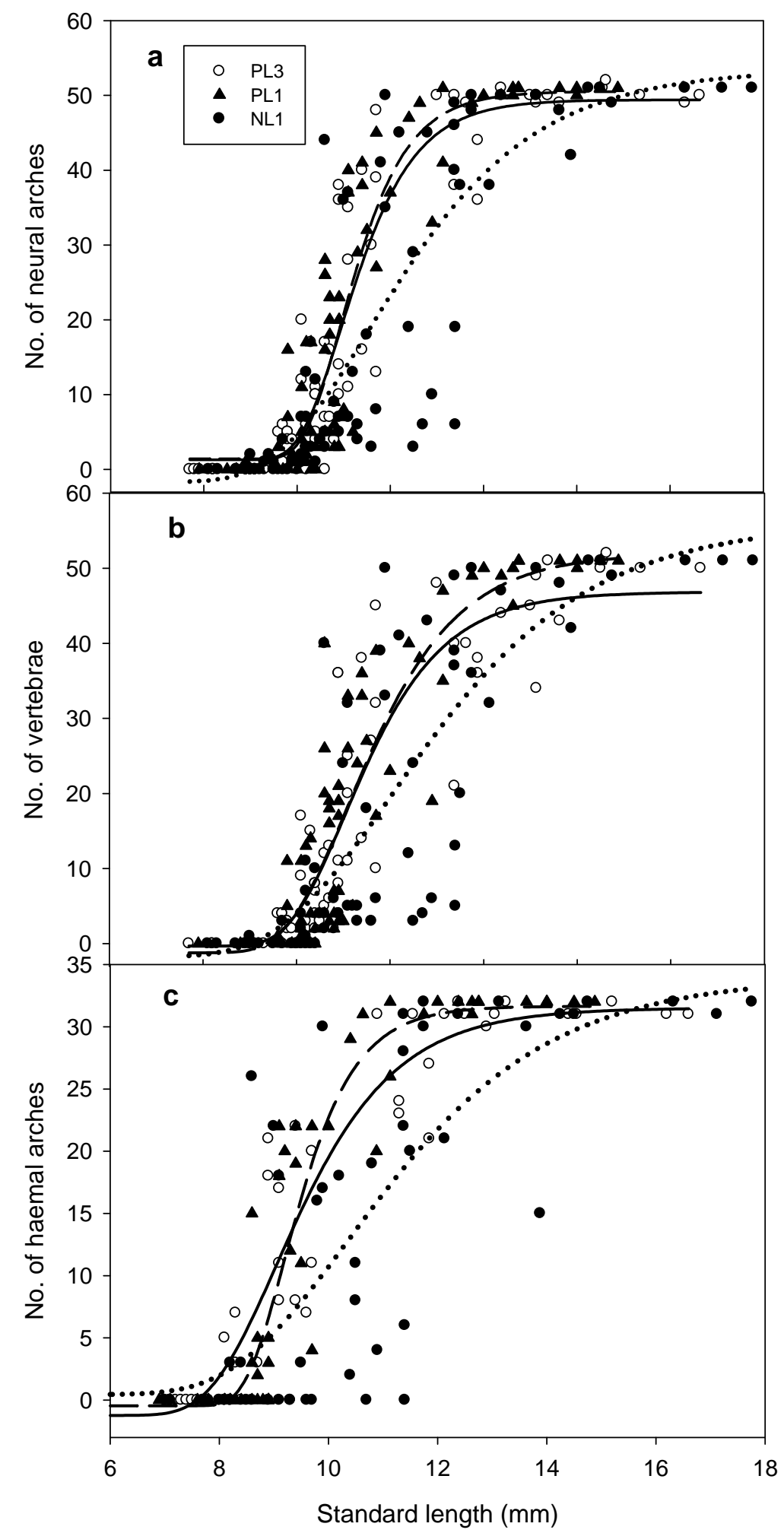

Figure 4: Number of neural arches (a), vertebrae (b), and haemal arches (c) undergoing ossification in cod larvae fed the experimental microdiets, in relation to diets and larval size. Each point represents one larva (21, 25, 31, 35 and $45 \mathrm{dph})$, and the best fit curve found was the Gompertz growth model. PL3: Slashed lines, PL1: solid lines, NL1: dotted lines. 

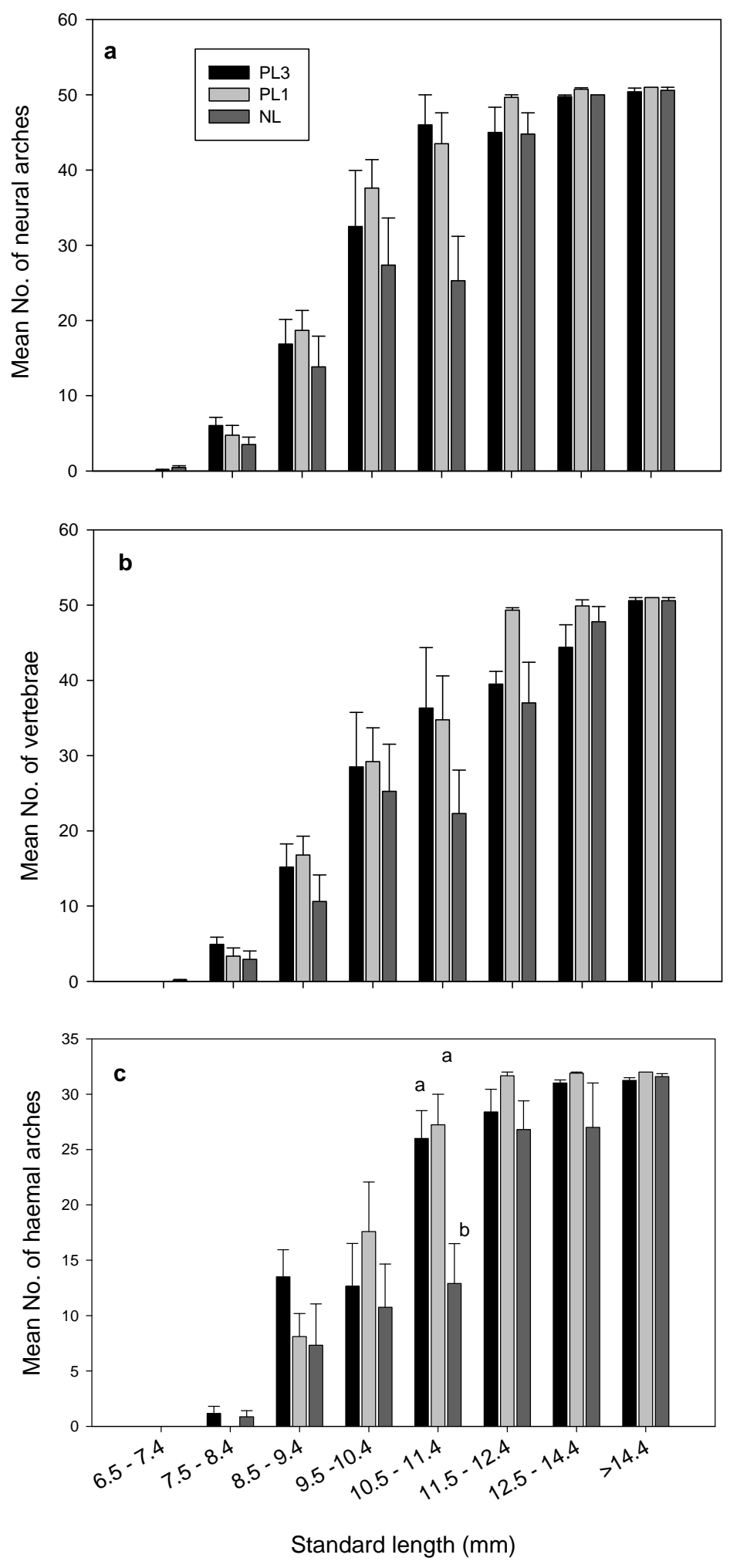

Figure 5: Mean number of neural arches (a), vertebrae (b), and haemal arches (c) undergoing ossification, in relation to diets and larval size inetrvals. Delayed ossification of haemal arches was found in NL1-larvae of 10.5-11.49 mm SL. Similar tendencies could e found for all ossifying elements of the vertebral column between SL of 8.5-11.5 mm, but individual variation within treatments was high. 


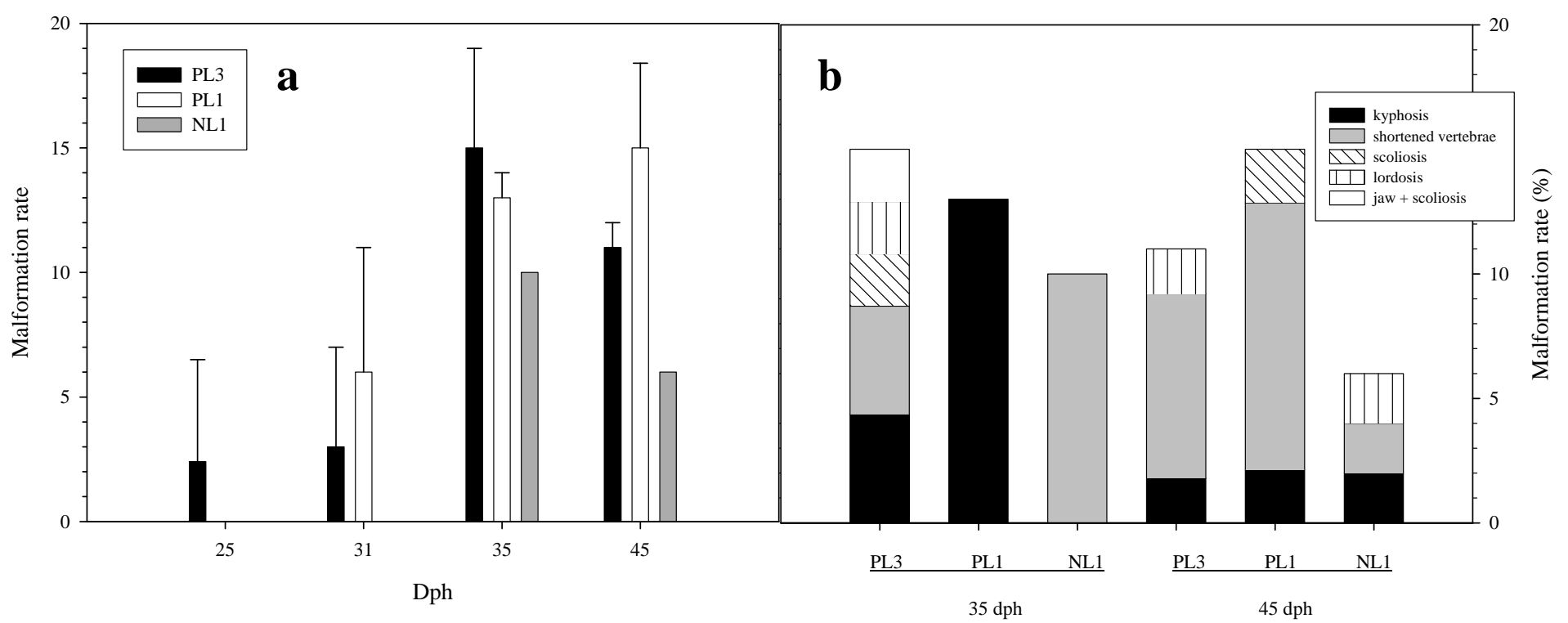

Figure 6. Skeletal deformities in cod larvae from the experiment. a) Percentage of cod larvae with deformities of the vertebral column from the different dietary treatments ( $\mathrm{n}=15 \times 3$ for each column). (b) Percentage of each vertebral deformity type found from each treatment on 35 and $45 \mathrm{dph}$. No differences were found between the treatments, giving a total of $11 \%$ spinal deformities in the larvae on $45 \mathrm{dph}$. 


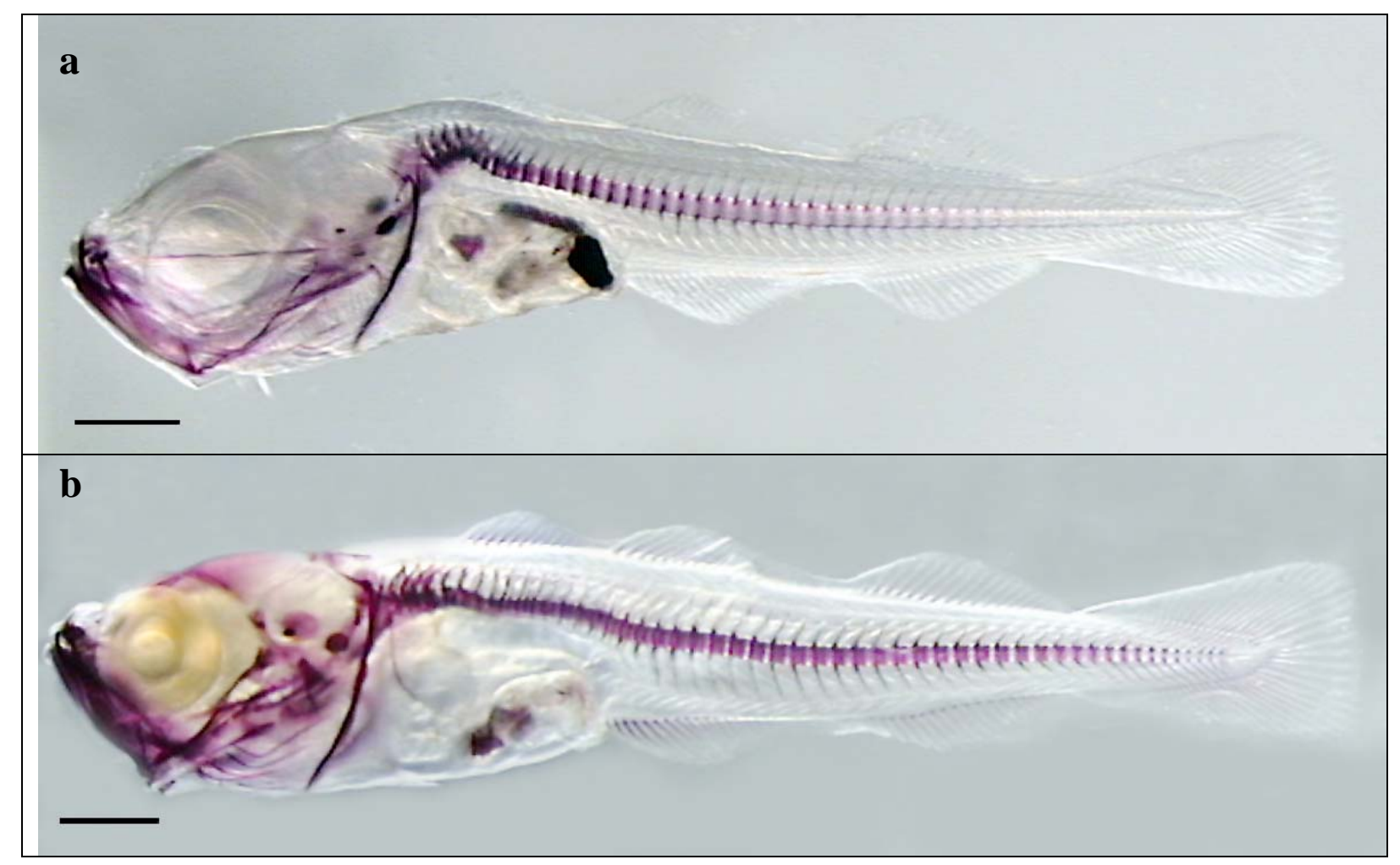

Figure 7: Skeletal deformities were found in $11 \%$ of the cod larvae at the end of the experiment (45 dph), with shortened vertebrae and kyphosis accounting for $81 \%$ of the spinal malformations. a) Kyphosis in larva fed NL1-diet. The first eight vertebral bodies and their respective neural arches were deformed. The centre of the deformation is located on the 4th vertebral body, resulting in an A-shape. b) A 45 dph larva (PL1) with fused, shortened and dislocated vertebral bodies in the anterior part of the spine and deformed neural arches of the involved vertebral bodies. The larvae were stained with Alizarin Red, and the calibration bars equals $1 \mathrm{~mm}$ 